\title{
PB-ADVISOR: A private banking multi-investment portfolio advisor
}

\author{
Israel Gonzalez-Carrasco, Ricardo Colomo-Palacios*, Jose Luis Lopez-Cuadrado, \\ Ángel García-Crespo, Belén Ruiz-Mezcua
}

Computer Science Department, Universidad Carlos III de Madrid, Av. Universidad 30, Leganés, 28911 Madrid, Spain

\section{A R T I C L E I N F O}

\section{Article history:}

Received 21 June 2011

Received in revised form 24 January 2012

Accepted 1 April 2012

Available online $\mathrm{xxxx}$

\section{Keywords:}

Semantic technology

Fuzzy logic

Recommender system

Investment portfolio

\begin{abstract}
A B S T R A C T
Private banking is a business area in which the investor requires tailor-made advice. Because of the current market situation, investors are requiring answers to difficult questions and looking for assurance from wealth managers. Private bankers need to have deep knowledge about an innumerable list of products and their characteristics as well as the suitability of each product for the client's characteristics to be able to offer an optimal portfolio according to client expectations. Client and portfolio diversity calls for new recommendation and advice systems focused on their specific characteristics. This paper presents PB-ADVISOR, a system aimed at recommending investment portfolios based on fuzzy and semantic technologies to private bankers. The proposed system provides private bankers with a powerful tool to support their decision process and help deal with complex investment portfolios. The system has been evaluated in a real scenario obtaining promising results.
\end{abstract}

\section{Introduction}

Private banking is a business area in which high net worth and/or high-income private individuals are offered tailor-made financial advisory, investment, and management services on a comprehensive, long-term basis [22] cited in [23]. The origins of the private banking sector can be traced back to London's goldsmith-bankers who, in the 17th century, were described as "Goldsmiths keeping Running Cashes" in other words, giving negotiable receipts in exchange for silver and other valuables [39] cited in [6]. In the 18th century, private banks targeted two distinct groups within London (UK). In the City, bankers such as Glyn Mills served the banking needs of merchants and manufacturers, whereas in the West End, bankers, such as Child \& Co and Drummonds, served the aristocracy and gentry [6].

Today, private banking can be described in terms of the services offered, the market environment, and the target group [23]. The services offered in private banking include traditional banking services as well as new added value services such as financial planning and alternative investments [69]. The private banking services differ from the financial services offered to individual customers in general [2]. These types of services are often long-term investments which are heterogeneous and highly complex, making it difficult for consumers to acquire enough knowledge about the services to be able to understand and influence their situation. Compared to retail banking customers, private banking customers are unique in that they have large deposits and high economic status. Consequently, banking executives have found that private banking customers require exceptionally high and consistent levels of service quality [50]. In short, private banking can be defined as a "high contact"' service, owing to the fact that customers' direct contact with service providers is relatively intense [50].

\footnotetext{
* Corresponding author. Tel.: +34 9162459 58; fax: +34 916249129.

E-mail addresses: israel.gonzalez@uc3m.es (I. Gonzalez-Carrasco), ricardo.colomo@uc3m.es (R. Colomo-Palacios), joseluis.lopez.cuadrado@uc3m.es (J.L. Lopez-Cuadrado), angel.garcia@uc3m.es (Á. García-Crespo), mbelen.ruiz@uc3m.es (B. Ruiz-Mezcua).
} 
Back in 2005 the market environment in private banking was favourable. Financial markets have recovered since 2003, but clients are now more conservative [44]. In today's environment,, obtaining top line revenue growth has become more difficult and achieving growth in client assets is becoming harder, with significant differences between onshore and offshore growth rates [44]. The target group of private banking is in practice often described in terms of the amount of the individual's wealth (core affluents, high net worth individuals, ultra high net worth individuals) and how they came by it (old rich versus new rich) [23]. Today, clients in private banking are becoming more sensitive to price and service quality and are better informed and less loyal to banking institutions and advisors [23]. Furthermore, private banking now finds itself in a more competitive environment with additional competition from newer business models such as family offices and hedge fund providers [43].

Although private banks world-wide in 2009 were challenged by shrinking margins, an overriding trend in profitability during this last year cannot be observed. Some markets with traditionally high margins are becoming more competitive, whereas others continuously show stable margins [8]. According to [60] with asset values down, lower trading volumes and clients focused on lower margin products, revenue prospects are severely reduced; thus, clients are expecting more from their wealth manager, asking difficult questions and looking for assurance. Moreover with the current economic recession, stakeholders' loyalty and support are very important to businesses [70].

Focused use of client relationship management (CRM) enabling tools and technology is now deemed to provide substantial competitive advantage. But CRM should support a true client-centric organization that addresses multiple channels with robust front-office technology tools [60]. For less wealthy clients, wealth managers are increasingly directing CRMs to follow specific advice-centric processes, thus, focusing their needs on recommendations and advisory systems. Following this trend, this paper presents PB-ADVISOR, a system based on fuzzy and semantic technologies, aimed at recommending investment portfolios to private bankers.

The paper consists of five sections and is structured as follows. Section 2 reviews the relevant literature. Section 3 discusses the main features of PB-ADVISOR, including the conceptual model, algorithmics and architecture. Section 4 describes the evaluation of the tool, including a description of the sample, the method, results and discussion. Finally, the paper ends with a discussion of research findings in Section 5, and in Section 6 concluding remarks are presented.

\section{Literature review}

Due to the increasing importance and maturity of Artificial Intelligence (AI), AI techniques and tools have been successfully used in a variety of business fields including marketing, accounting, management information systems and production management [11]. As a result, several works reflect the importance of AI as a support for financial issues. Within this area, there are several works that report interesting results: stock behaviour prediction (e.g. [12,61]), bankruptcy (e.g. [57]), credit scoring (e.g. [75,81]), financial crises and failures (e.g. $[9,46])$ and credit card fraud (e.g. $[72,74])$ to cite the most popular and recent cases.

In the field of investment recommendation and portfolio selection and composition, the attractiveness of the field has led to many other initiatives. As is known a portfolio is a distribution of wealth among several investment assets such as stocks, bonds, and their derivatives. In this area, the use of genetic algorithms (e.g. [13,41,42,52]), fuzzy logic (e.g. $[31,36,53,54,59,63,73,77])$, neural networks (e.g. $[20,76,25,47])$, decision support systems (e.g. $[40,53,37,65]$ ) among several other techniques has proven to be just as effective in financial portfolio selection.

Focusing on fuzzy logic, one of the components of PB-ADVISOR, several authors have recommended the incorporation of fuzzy theory into the interpretation of portfolio matrices with different applications: e.g. to optimize the selection of portfolio products [31], to obtain optimal proportions of the assets for constructing a portfolio that respects investor-preferences [36], for strategic management [53], to assist managers in reaching a better understanding of the overall competitiveness of their business portfolios [54], to facilitate the interpretation of portfolio matrices used for strategy alternative(s) formulation and selection [59], to solve the portfolio problem when security returns are bifuzzy variables [73] and to define new dynamic portfolio selection strategy in the stock market [77].

Given that the investments market is a very complex environment, returns cannot always be accurately predicted from historical data, as they are beset with ambiguity and vagueness [41]. Therefore, fuzziness is useful to introduce vague goals for the expected return rate and risk in such environments.

For a rational investor, the leitmotiv to ensure an increase in wealth is to diversify risk [56]. But in a world in crisis with asset values down, the work of private bankers has been dramatically altered: clients are expecting more from their wealth manager, asking difficult questions and looking for assurance [60]. To deal with this situation, private bankers need to seek alternative products to build a more diverse portfolio, including a wider range of products that cannot be controlled in a traditional way, thus requiring new recommendation systems centered on advice rather than trading. This system must be open to new products (real estate, gold, etc.) along with traditional ones (bonds, stock, etc.) in order to be able to produce more general and specific investment recommendations based on customer and product profiles. These recommendations must be made to the private banker, who will be responsible for transmitting this information to his or her customers; this system thereby gives his or her advice an added value. With the aim of responding to this need, this paper presents PB-ADVISOR, a tool based on fuzzy logic theory, semantic ontologies and expert systems. 


\section{PB-ADVISOR: private banking portfolio recommendations}

The interest in knowledge representation of investments portfolio is not new. Shyng et al. [64] classify personal investment portfolios as either conservative, moderate or aggressive. These authors establish the main categories for each one and highlight the principal factors related to these types of investment. In addition, this work analyzes the influence of emotions on the composition of investment portfolios. The literature reveals that psychological biases affect investor behaviour and prices [58]. As a consequence of this influence, dealing with an investor's psychological biases is a complex problem for investment advisors. Another important factor in investment is risk tolerance. Both factors are part of the PB-ADVISOR approach.

In PB-ADVISOR, the authors propose a multi-investment recommendation system based on semantic technologies and fuzzy logic. By combining both technologies with faceted searching, the system provides private bankers with tailor-made recommendations for their clients, based on their characteristics. The proposed system will provide the private banker with the most suitable portfolio for each investor, taking into account investor preferences and risk tolerance. The main steps of the proposed recommendation process are:

1. Investor categorization based on facets.

2. Determining the investor profiles based on social and psychological characteristics using Semantic and Fuzzy Logic approaches.

3. Investment categorization based on facets.

4. Investment (portfolio) classification based on Semantic and Fuzzy Logic approaches.

5. Matching the portfolio characteristics with the investor categories.

6. Obtaining a rich recommendation based on XBRL (eXtensible Business Reporting Language).

Private bankers deal with clients from different environments. Despite the common criterion of maximizing benefit, clients usually feel more confident with other criteria such as the security of the investment. In these cases the risk profile and the psychological characteristics of the investor play an important part in the investment decision. Expert private bankers are able to recognize the profile of the investor and offer the best option. However, this point is highly subjective. For this reason, PB-ADVISOR is based on the risk tolerance of the investor in addition to other parameters such as profitability.

The categorization of the investor and the investments is made using Faceted Classification. The characteristics of both investors and portfolios are represented by two domain ontologies, and the relationship between the investor profile and the desirable characteristics of the portfolio are represented by fuzzy rules. Finally, the output of the system is encapsulated under the XBRL standard. The following subsections detail each of the proposed steps.

\subsection{Faceted classification and semantic annotation}

Faceted classification is an approach to the organization of information with origins in the field of library and information science. Faceted classifications are increasingly common on the World Wide Web, especially on commercial web sites [1]. In addition, they have been used to assist automated search and retrieval of information [10], to improve Web navigation [68], and have been extended to other fields and knowledge domains such as manufacturing process selection [32] as well as being used in collaboration with AI techniques [51].

A subject domain is first analyzed into component facets, and relevant facets are then synthesized into combinations to characterize items of interest. The flexibility of faceted classification lies in its ability to describe a large number of items within the subject domain, including novel items, on the basis of a relatively economical and pre-defined set of facets and terms. The facets do not need to be ordered, nor be of the same type, although they should be clearly defined and mutually exclusive.

Furthermore, faceted classification and ontologies offer a consistent structure for organizing resources effectively to use them on the Web. Faceted Classification has become of interest in organizing resources on the Web because it does not establish the relationships between classes, and the ontologies can formally express such relationships among fundamental concepts. Therefore, these approaches are more effective than traditional classifications for describing the kind of diverse and multidisciplinary subjects that are commonly found on the Web. In this sense, semantic approaches and faceted classification have been used in the semantic related literature $[27,29]$ in order to establish the classification and the relationship of diverse and multidisciplinary subjects.

PB-ADVISOR incorporates these two approaches to improve and computerize the interaction with the private banker and the financial experts. These users will categorize the investor and the investment portfolio through the Web Interface of the Faceted Classification component. Afterwards, PB-ADVISOR determines the investor profile and the most interesting investment recommendations through semantic annotation and ontologies.

\subsection{Semantic component. investor and investment categorization}

PB-ADVISOR begins its duties with the categorization of the investor based on fuzzy logic and ontologies. The different characteristics to be 'fuzzified' for the investor categorization have been obtained from the literature and are based on two different perspectives: social and psychological issues. 
Both aspects are obtained by the faceted classification process of PB-ADVISOR and the interaction of the private banker and the financial experts. This faceted classification has been designed based on the research of Grable and Lytton $[34,35]$, creating an interactive process to classify the investor. Therefore, taking into account these and the faceted classification process developed, PB-ADVISOR determines the investor profile automatically with respect to the risk tolerance.

In order to gather all these aspects in a unified way, the use of an ontology is required. This ontology represents the social attributes of the investor (Figs. 1 and 2), such as gender, incomes or marital status. Apart from that, the ontology permits representation of psychological aspects such as self-esteem, emotion during risk, etc. (Figs. 3 and 4). The design of this ontology is based on previous literature, e.g. [33,35,66].

After the investor classification, the categorization of the products in the portfolio must be performed according to a set of characteristics. The characteristics of each product have been adapted from the FEF ontology [45] and the taxonomy of Gupta el al. [36]. Thus, each financial product is labeled according to a common vocabulary.

Fig. 5 shows the investment ontology. This ontology represents the characteristics of the investment, such as volatility, liquidity, product or product risk. Based on these characteristics, it is necessary to determine which financial products coincide with the risk tolerance of the investor. To do so, each investment is classified according to some variables: product risk, interest rate risk, reference interest risk, operational risk, liquidity, volatility, short term return and long term return (all

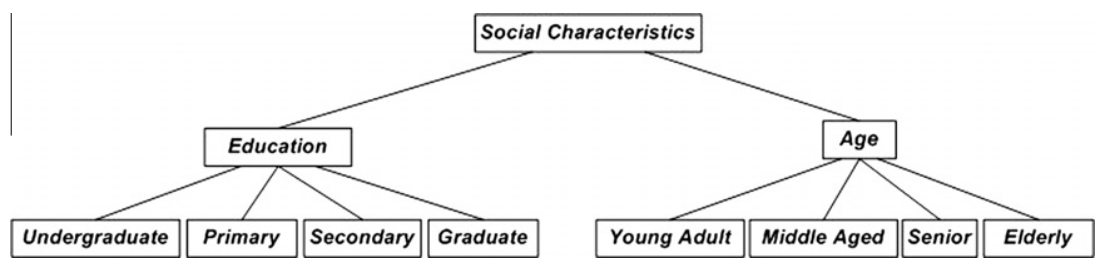

Fig. 1. Investor ontology - social characteristics (partial view - 1).

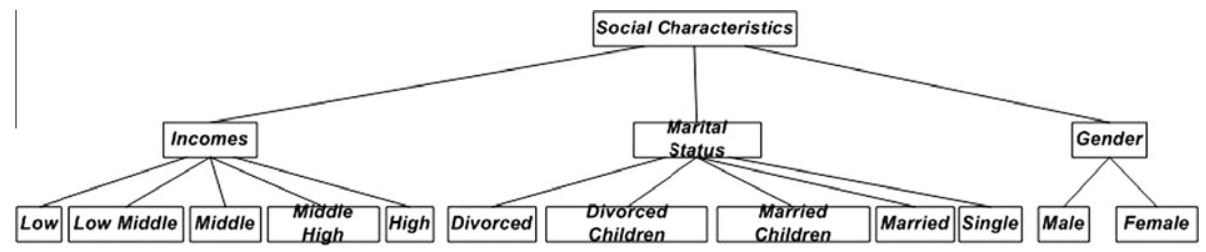

Fig. 2. Investor ontology - social characteristics (partial view - 2).

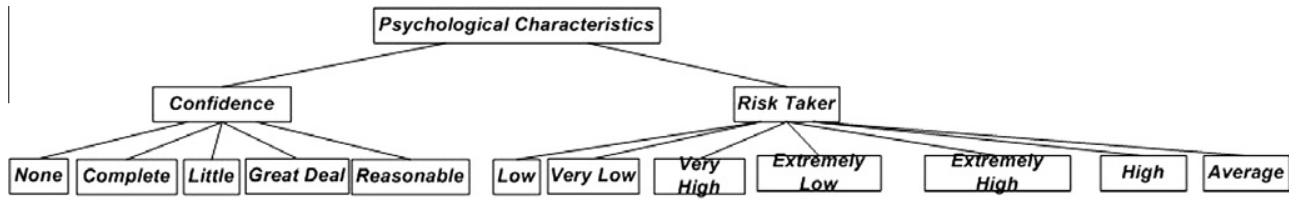

Fig. 3. Investor ontology - psychological characteristics (partial view - 1).

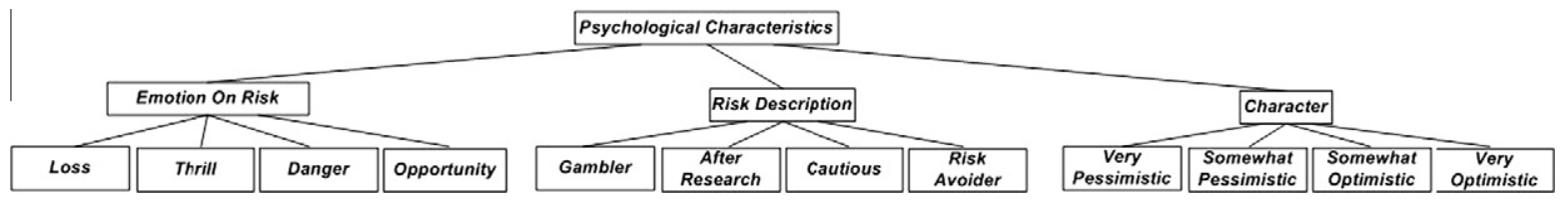

Fig. 4. Investor ontology - psychological characteristics (partial view - 2).

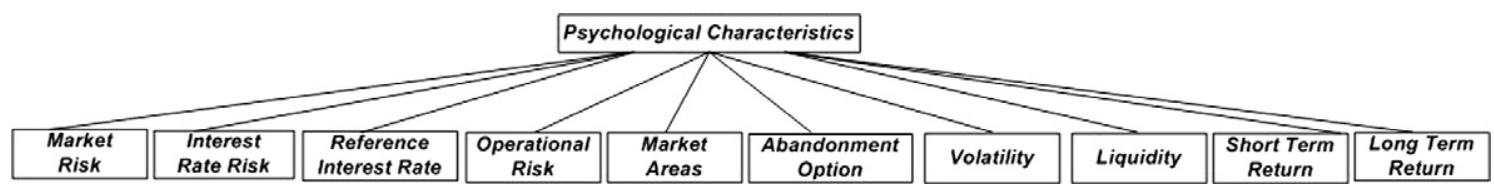

Fig. 5. Portfolio investment ontology. 
broken down with the labels Low, Average and High).The abandonment option is labeled true or false and, finally the product is divided into: Prime Retail Real Estate, Land, Mall Retail Real Estate, Building Real Estate, Fixed Term Deposits, Structured Deposits, Currency Deposits, Bonds, Startup Investments, and Solar Farms.

The characteristics of the financial products in the portfolio will be categorized with linguistic labels using fuzzy sets according to the same terms employed in the investor categorization: Defensive, Conservative, Moderate and Aggressive.

\subsection{Fuzzy logic component. Investor profile estimation and investment categorization}

Once the investor profile has been defined using the Faceted Classification and it has been categorized in the semantic process, the Investor Profile Estimation based on Fuzzy Logic begins. However, the evaluation of the investor risk tolerance requires certain knowledge and implies the subjective point of view of a financial advisor. For example, Grable and Lytton establish a score for each response in a questionnaire and the sum of all the scores determines the investor profile [34]. The categorization process is highly subjective and it is difficult to precisely determine the category for a given investor. For this reason, the previously mentioned categories have been 'fuzzified' for ease of expression and to determine the rules of membership based on the expertise of an investor advisor.

Briefly, the fuzzy sets theory provides a framework for the representation of the uncertainty of many aspects of human knowledge. Nowadays, fuzzy rule based systems are being successfully applied to a wide range of real-world problems from different areas and in many real-world applications. Although a system can be defined mathematically in a general sense, a fuzzy logic system representation is still preferred by engineers [55].

PB-ADVISOR will characterize investors according to their tolerance for risk, depending on their social and psychological characteristics. This will create a set of fuzzy rules to define the investor Risk Tolerance $\left(\mathrm{RI}_{\mathrm{Inv}}\right)$ from two clusters of variables: Social Behaviour (SB) and Psychological Behaviour (PB).These sets of variables were defined from the characteristics obtained through questionnaires and included in the faceted classification process. Two examples of these sets, SB and PB, are depicted below:

$$
\begin{aligned}
\mathrm{RI}_{\text {Inv }}= & \mathrm{SB}\{\text { Age, } \text { Incomes, Marital Status, Gender and Education }\} \text { AND } \\
& \mathrm{PB}\{\text { Confidence, } \text { Character, Risk Taker, Emotion On Risk, Risk Description }\}
\end{aligned}
$$

Some of the variables of the previous SB and PB clusters could be characterized by fuzzy values, which would lead to a fuzzy set for each of the variables. Therefore, in the design and implementation of a fuzzy logic system, there is an option to choose which of the three most popular membership functions to use: triangular, Gaussian or trapezoidal. In this paper, the triangular and trapezoidal membership functions have been used for the fuzzy sets. Using these functions means that the performance rate will be very fast, although the level of accuracy will be lower than with either of the membership functions.

Focusing on the SB cluster, the membership function of the fuzzy variables, age and income, are adapted from $[15,16]$ respectively. In these fuzzy sets, the labels and values for each characteristic are obtained from the cited questionnaires. The age and income variables have been defuzzified because they have continuous numerical values. The domain of discourse associated with the fuzzy sets of the SB cluster has been adapted from [66] and is as follows: Defensive, Conservative, Moderate and Aggressive. The rest of the variables of the SB cluster (marital status, gender and education) used to characterize the investor are categorical and do not need to be fuzzified.

The psychological variables of the PB cluster, such as sensation-seeking and self-esteem, have linguistic labels and have been defuzzified to obtain numerical values. The universe of discourse associated with the PB fuzzy sets for psychological risk aversion has been adapted from that proposed by Grable and Lytton [35] to fit with the SB fuzzy sets: Defensive (Low), Conservative (Below-average), Moderate (Above-average) and Aggressive (High).

The traditional notation for the fuzzy sets was defined by Lotfi Zadeh [78] and has been used in PB-ADVISOR for the definition of the PB and SB sets. After defining these fuzzy sets, the fuzzy inference rules may be used to represent the relation between these fuzzy sets.

The first step in the fuzzy component of PB-ADVISOR is the definition of a number of fuzzy rules to describe investors socially. Taking into account the number of variables of the SB and PB sets, a large number of rules are generated. An example of these types of rules to define the aggressive investors according to their social characteristics would be:

\section{IF Age is Middle Aged AND Gender is Female AND Marital Status is Married THEN Investor is Socially-Conservative}

It is generally believed that younger investors take greater risks in anticipation of higher returns. With increasing age, they rebalance the portfolio in favor of safer and more secured (though somewhat lower) returns. In the finance literature, it is held that women invest more conservatively and are less likely to hold risky assets than men. They do not rebalance their portfolios frequently and prefer a buy-and-hold strategy. Finally, there are marital-status influences on consumption, savings and investment behaviour.

The psychological fuzzy rules are similar and define each investor within the same domain. For example:

IF Risk Taker is Average AND Confidence is Little AND Emotion On Risk is Danger THEN investor is Psychologically-Conservative 
To be able to obtain the full set of social rules that model this problem, all theoretically possible combinations of $P_{t}$ rules were considered, taking into account the number of antecedents $p$ and the number of input fuzzy sets $A_{p}$ considered for each antecedent. Thus, for each consequent, the theoretical number of possible rules is:

$$
P_{t}=\prod_{n} A_{n} \quad \text { for } n=1 \ldots p
$$

In addition, linguistic labels have been traditionally used as modifiers of fuzzy sets - equivalent to what would be the natural language adverbs. The interpretation in the fuzzy model of these statements is the composition of the membership function with a simple arithmetic operation.

Many approaches to linguistic approximation have been developed with the use of sets of predefined primary terms (e.g. small, medium, large), linguistic modifiers or hedges (e.g. not, much, very, more or less) [48]. Linguistic modifiers produce a semantic alteration of the fuzzy set: for example, traditional linguistic modifiers such as very or fairly produce concentration or dilation respectively. In other words they might both increase and decrease the uncertainty. Concentrations tend to concentrate the elements of a fuzzy set by reducing the degree of membership of all elements that are only "partly" in the set [62]. For this purpose, the original membership function is raised to a value $p$, since $p>1$. Dilations stretch or dilate a fuzzy set by increasing the membership of elements that are "partly" in the set. For this purpose, the original membership function becomes the nth root or the $p$ value is raised such that $p €[0,1,83]$.

In this research the authors have used the linguistic adverbs or modifiers defined in Table 1.

The membership functions included in Table 1 have been calculated taking into account the linguistic approximation proposed by Eshragh and Mamdani [19] and Lakoff [49]. Hence, with these new linguistic labels, very, 'highly', fairly, somewhat and 'a bit' (sorted by relevance), there will be fine-tuning of the categorization of risk that an investor takes, both at a social and psychological level.

After the definition of the fuzzy component of PB-ADVISOR, a matrix was constructed to gather the social and psychological factors of the investor The motivation for this matrix is the Business Portfolio Analysis Matrix [17,67], a tool that uses quantified performance measures and growth targets to analyze a firm's business units (called strategic business units, or SBUs, in this analysis) as though they were a collection of separate investments. The Business Portfolio Analysis Matrix is one of the most important instruments used in the literature as an analytical and strategic tool to maintain the financial sustainability of a business $[4,5,7,18]$. Furthermore, several authors have recommended the incorporation of fuzzy theory into the interpretation of portfolio matrices to assist managers in different scenarios and tasks, e.g. [31,36,53,54,59,73,77].

In this proposal, the vertical axis represents the social behaviour (instead of the market growth rate) and the horizontal axis symbolizes the psychological behaviour (instead of the relative market share). Following the position of the labels in the business portfolio analysis, the labels for the SB and PB sets are placed in the matrix based on relevance. Accordingly, in PBADVISOR, the Business Portfolio Analysis Matrix gives a series of quadrants that locate the investor's risk tolerance within these two dimensions. The fine-tuning (performed by the linguistic adverbs) can move the location of an investor within the same quadrant, bringing it closer to its adjacents.

Thus, the fine-tuning performed by the linguistic adverbs for investor 1 can be summarized in the following rule:

[Investor 1] fairly Conservative (social) AND highly Conservative (psychological)

Finally, for the following investor categorization "fairly Socially-Conservative and highly Psychologically-Conservative" the graphical example of this behaviour is shown in Fig. 6.

Each quadrant is divided into sections that correspond to the linguistic labels explained previously. The numerical conversion of these labels can be seen in Fig. 6, and corresponds with a value in the range [0-1].

Traditionally, research on portfolio recommendation has focused on financial rather than psychological aspects of the investor. However, in order to fully satisfy investor expectations it is important to take into account investor feeling regarding the investment.

In this sense, the 'fuzzification' of the rules of financial product selection is based on the concept of matrices (see Fig. 7 for further details) as well as on a set of fuzzy rules to describe portfolio investment. These rules have been obtained with the expertise of an investor advisor for Spanish investors. Examples of these types of rules, according to their characteristics, would be:

Table 1

Linguistics adverbs included in PB-ADVISOR.

\begin{tabular}{ll}
\hline Linguistic adverb & Membership function \\
\hline Very & $\mu_{\text {very } \mathrm{A}}(x)=\left(\mu_{\mathrm{A}}(x)\right)^{2}$ (Concentration of the fuzzy set) \\
Highly & $\mu_{\text {highlyA }}(x)=\mu_{\mathrm{A}}^{5 / 4}(x)$ (Concentration of the fuzzy set) \\
Fairly & $\mu_{\text {regularA } \mathrm{A}}(x)=\mu_{\mathrm{A}}^{3 / 4}(x)$ (Dilation of fuzzy set) \\
Somewhat & $\mu_{\text {someA } \mathrm{A}}(x)=\mu_{\mathrm{A}}^{1 / 2}(x)$ (Dilation of fuzzy set) \\
A bit & $\mu_{\text {someA }}(x)=\mu_{\mathrm{A}}^{1 / 4}(x)$ (Dilation of fuzzy set) \\
\hline
\end{tabular}




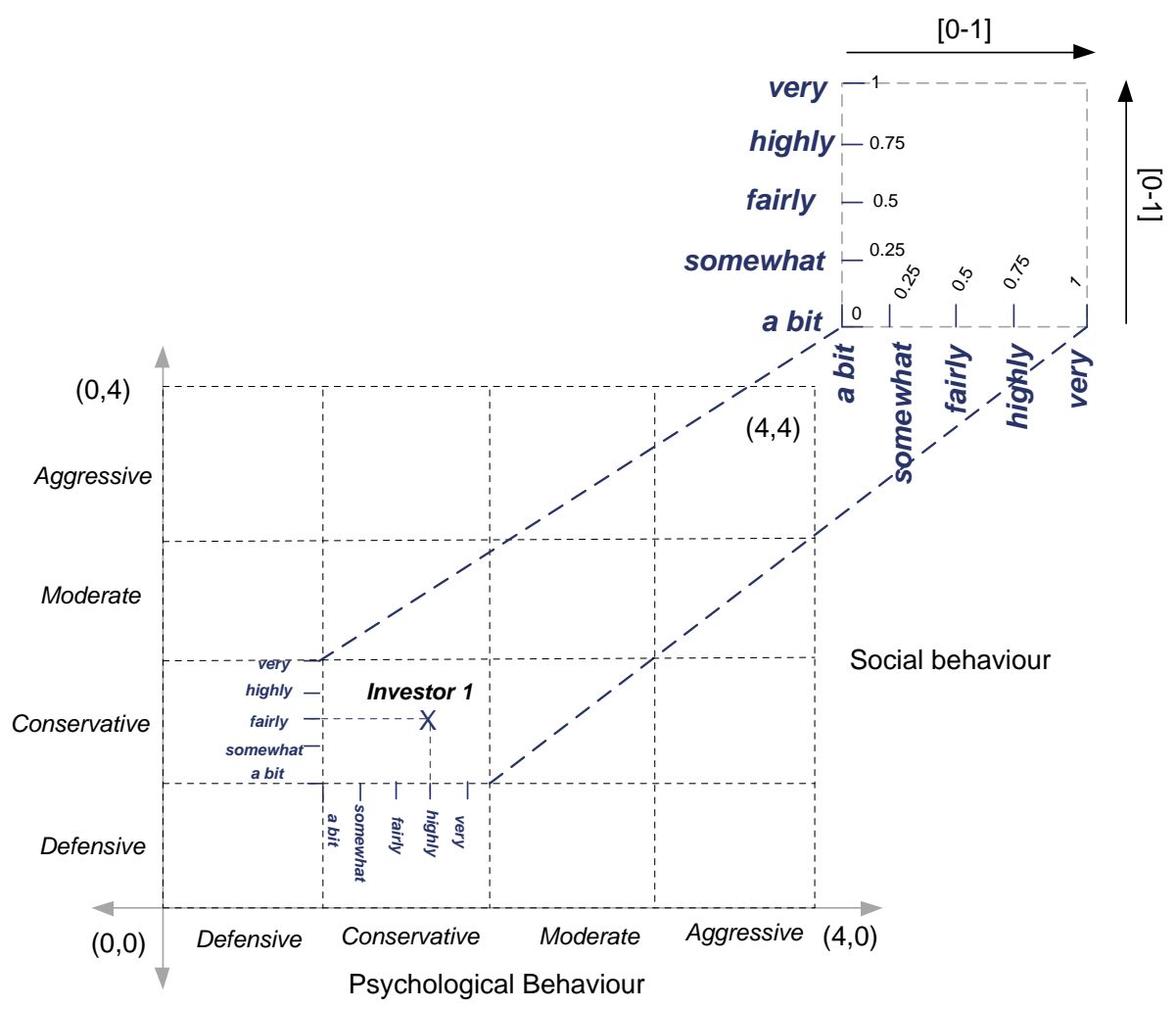

Fig. 6. Bi-dimensional matrix for investor behaviour.

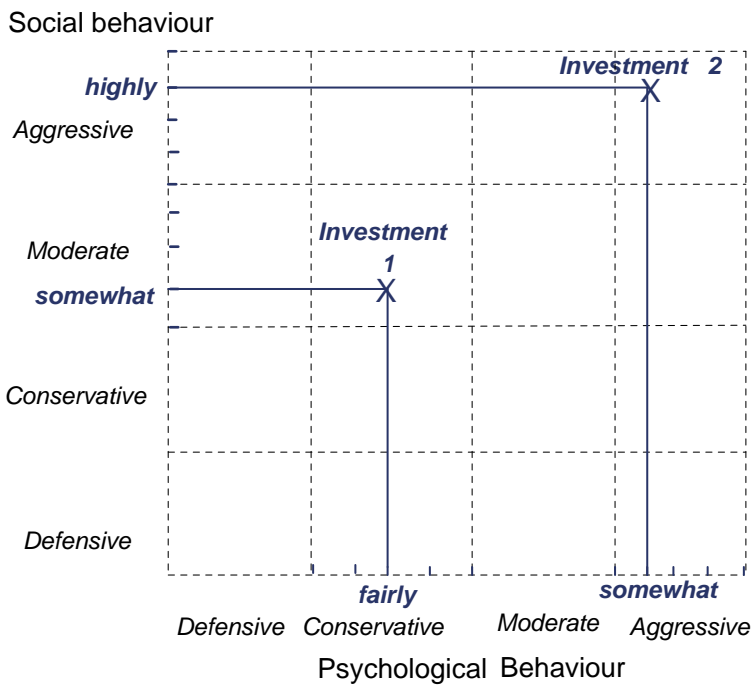

Fig. 7. Fuzzy portfolio matrix based on investor's risk tolerance.

[Investment 1] IF Liquidity is moderate AND Product is Prime Retail Real Estate AND Volatility is normal THEN investment is Socially-Moderate and Psychologically-Conservative

[Investment 2] IF Product Risk is low AND Liquidity is low AND Product is Solar Farms AND Long Term Return is low THEN investment is Socially-Aggressive and Psychologically-Aggressive

The linguistic labels, very, highly, fairly (not labeled), somewhat and a bit, allow fine-tuning in the categorization of investment risk. The membership functions of these modifiers or hedges are defined in Table 1 . The variables Product (Prime 
Retail Real Estate, Land, Mall Retail Real Estate, etc.), Abandonment Option (yes or no), Operational Risk (high, medium or low), Interest Rate Risk (high, medium or low) and Product risk (high, medium or low) are not fuzzy because they have categorical values. The membership functions for the remaining investment variables have been defined by the expert.

Finally, a matrix has been constructed which represents the fuzzy investment categorization based on the social behaviour (vertical axis) and the psychological behaviour (horizontal axis) of the investor. This provides a series of quadrants that enable each investment to be located according to the investor's risk tolerance. In addition, the fine-tuning (performed by the linguistic adverbs) can move the location of an investment within the same quadrant, bringing it closer to its adjacents. An example of this behaviour can be observed through the following investment (Investments 1 and 2 in Fig. 7):

[Investment 1] somewhat Moderate (social) and fairly Conservative (psychological)

[Investment 2] highly Aggressive (social) and some Aggressive (psychological)

\subsection{Investor and investments matching and products recommendation}

At this point, PB-ADVISOR could provide a set of investments for the investor taking into account the social and the psychological features of both investor and investments. However, the recommendation made by the system would be imprecise because PB-ADVISOR will only return recommendations that are very close within the same quadrant. For this reason and using the knowledge obtained in the research of Ghazinoorya et al.[31], a series of geometric concepts will be used to define areas of influence in the matrices around each investor or investment. This means that an investor or investment can form relationships with various quadrants in each matrix, thereby allowing greater freedom of choice for the recommendation system.

To obtain the figure associated with the area of influence, the system will calculate the possible shift or offset, in each of " $x$ " and " $y$ " axis, from the point at which the investor or investment is located within the fuzzy matrix. Therefore, the area of influence appears as an ellipse whose horizontal axis corresponds to the psychological characteristics and the y-axis to the social ones. The ellipse is characterized by the point where the investment or the investor is located within a quadrant $\left(x_{0}, y_{0}\right)$ and the two semi-axes that correspond to the freedom of decision (FD) in the social and psychological direction. The offset associated with this equation is as follows:

$$
\left(F D_{\text {Investor/Investment }}\right)=\left(\text { offset }_{x}, \text { offset }_{y}\right)=\left(\text { Eval }_{\text {psyco }}, \text { Eval }_{\text {social }}\right)=\left(\left(\left(\sum_{i=1}^{n} w_{i}\right) / n\right) / 2,\left(\left(\sum_{j=1}^{k} w_{j}\right) / n\right) / 2\right)
$$

where $i$ and $j$ are the social and psychological characteristics. The geometrical fine-tuning to move inside a quadrant within the range [0-1] is obtained by using the values of the weights $W$ shown in Table 2 . These values are determined for each Psychological and Social variable by the expert based on his knowledge and expertise.

For example, for the investor profile defined in the rules (2) and (3) the offset ${ }_{x}$, and offset $t_{y}$ will be assessed only for the columns Socially-Conservative and Psychologically-Conservative, based on the weights associated with the correct values of the characteristics of the investor. The calculation process applied for investor 1 defined in rules (2) and (3) (or Fig. 6) is the following:

$$
F D_{\text {Investor } 1}=\left(\text { offset }_{x}, \text { offset }_{y}\right)=\left(\text { Eval }_{\text {syyco }}, \text { Eval }_{\text {social }}\right)=((0.910 / 3) / 2,(2.102 / 3) / 2)=(0.15,0.35)
$$

Table 2

\begin{tabular}{|c|c|c|c|c|c|}
\hline & & Aggressive & Moderate & Conservative & Defensive \\
\hline \multicolumn{6}{|c|}{ Psychological behaviour } \\
\hline \multirow[t]{2}{*}{ Characteristic 1} & Value 1 & Weight [0-1] & Weight [0-1] & Weight [0-1] & Weight [0-1] \\
\hline & Value $n$ & Weight [0-1] & Weight [0-1] & Weight [0-1] & Weight [0-1] \\
\hline \multirow[t]{2}{*}{ Characteristic $n$} & Value 1 & Weight [0-1] & Weight [0-1] & Weight [0-1] & Weight [0-1] \\
\hline & Value $n$ & Weight [0-1] & Weight [0-1] & Weight [0-1] & Weight [0-1] \\
\hline \multicolumn{6}{|l|}{ Social behaviour } \\
\hline \multirow[t]{2}{*}{ Characteristic 1} & Value 1 & Weight [0-1] & Weight [0-1] & Weight [0-1] & Weight [0-1] \\
\hline & Value $n$ & Weight [0-1] & Weight [0-1] & Weight [0-1] & Weight [0-1] \\
\hline \multirow[t]{2}{*}{ Characteristic $k$} & Value 1 & Weight [0-1] & Weight [0-1] & Weight [0-1] & Weight [0-1] \\
\hline & Value $n$ & Weight [0-1] & Weight [0-1] & Weight [0-1] & Weight [0-1] \\
\hline
\end{tabular}

Weight table for social and psychological characteristics (investor and investment). 
Then, the area of influence around each investment or investor in the matrices will be calculated using an ellipse with center $\left(x_{0}, y_{0}\right)$, horizontal deviation $\left(x_{0}-\right.$ offsetx,$x_{0}+$ offsetx $\left.x^{\prime}\right)$ and vertical deviation $\left(y_{0}-\right.$ offsety, $y_{0}+$ offsety' $)$.

For the ellipse associated with the area of influence the equation of an ellipse in Cartesian coordinates with the center at point $\left(x_{0}, y_{0}\right)$ is used:

$$
\left(x-x_{0}\right)^{2} / a^{2}+\left(y-y_{0}\right)^{2} / b^{2}=1
$$

where $a>0$ and $b>0$ are the semi-axes of the ellipse ( $a$ corresponds to the $x$-axis and $b$ corresponds to the $y$-axis) and correspond to the offset on the $x$-axis and the offset on the $y$-axis, respectively.

Therefore, in the example of investor 1 , the ellipse will have the horizontal deviation $\left(x_{0}-0.15, x_{0}+0.15\right)$ for psychological characteristics and vertical deviation $\left(x_{0}-0.35, x_{0}+0.35\right)$ for social characteristics. The values $x_{0}$ and $y_{0}$ are obtained through the fuzzy process defined in the Fuzzy Logic-Based Investor Profile Estimation (Section 3.3).

PB-ADVISOR applies this calculation process for each investment of the portfolio to make the matching between the investor and the investments and to thus offer a suitable recommendation.

Following with the example of Investor 1, Fig. 8 shows the areas of influence over the fuzzy matrices for this investor (based on rules (2), (3) and (5) and Fig. 6) and the investments 1 and 2 (based on rules (6)-(9) and Fig. 7).

To find the recommendation of investments that best fits the characteristics of an investor, the investment and investor are both represented by means of a matrix structure (Fig. 8). In such a matrix structure, the columns represent the psychological behaviour and the rows represent the social behaviour. The product will be represented in this matrix structure in the form of ellipses. Investors will also be represented according to their social and psychological characteristics. In this way, both investors and investments are plotted into the matrix according to their characteristics. As shown in Fig. 9, once the ellipses for representing investments and investors have been plotted, they can overlap each other. This overlap, along social and psychological lines, will occur between areas of influence of both products and investors (Fig. 9).The more overlapped area between an investment and an investor, the more suitable the investment for that investor. If investment ellipses do not overlap the investor ellipse, then the suitability of the investment can be measured by means of the distance between ellipses: the nearer the investment, the more suitable it is for the investor.

To prioritize the recommendations of the portfolio, it has to be determined whether or not there is an overlap between the areas of influence of the investor and the investment. In the first instance, the priority is defined according to the percentage of overlap of each product with the investor: a higher percentage means a higher priority. In the second instance, in the absence of overlap, the distance between the different ellipses of investment and the investor will be calculated: a shorter distance implies the highest priority. In this case, the minimum distance is defined following the Euclidian equation:

$$
\sqrt{(x-a)^{2}+(y-b)^{2}}
$$

where $(x, y)$ denotes a generic point of the ellipse of the investor and $(a, b)$ a generic point of the ellipse of the investment. Thus, the expression associated with the minimum distance by the partial derivatives of each variable must be minimized:

$$
f(x, y, a, b)=(x-a)^{2}+(y-b)^{2}=f^{\prime}(x)=d x f\left\{\begin{array}{l}
f^{\prime}(x)=d x f(x, y, a, b) \\
f^{\prime}(y)=d x f(x, y, a, b) \\
f^{\prime}(a)=d x f(x, y, a, b) \\
f^{\prime}(b)=d x f(x, y, a, b)
\end{array}\right.
$$

where $f(x, y, a, b)$ reaches extreme values are the solutions of the proposed system.
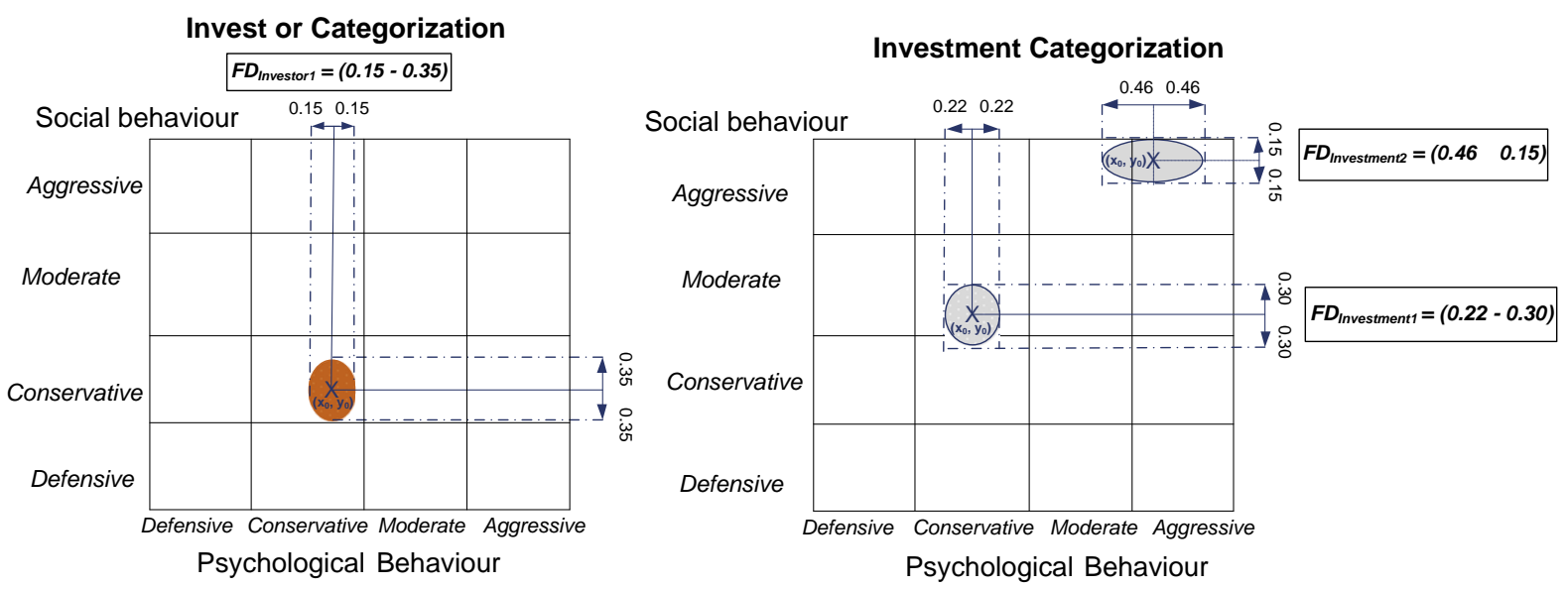

Fig. 8. Geometrical approximation for the area of influence in investor and investment matrix. 

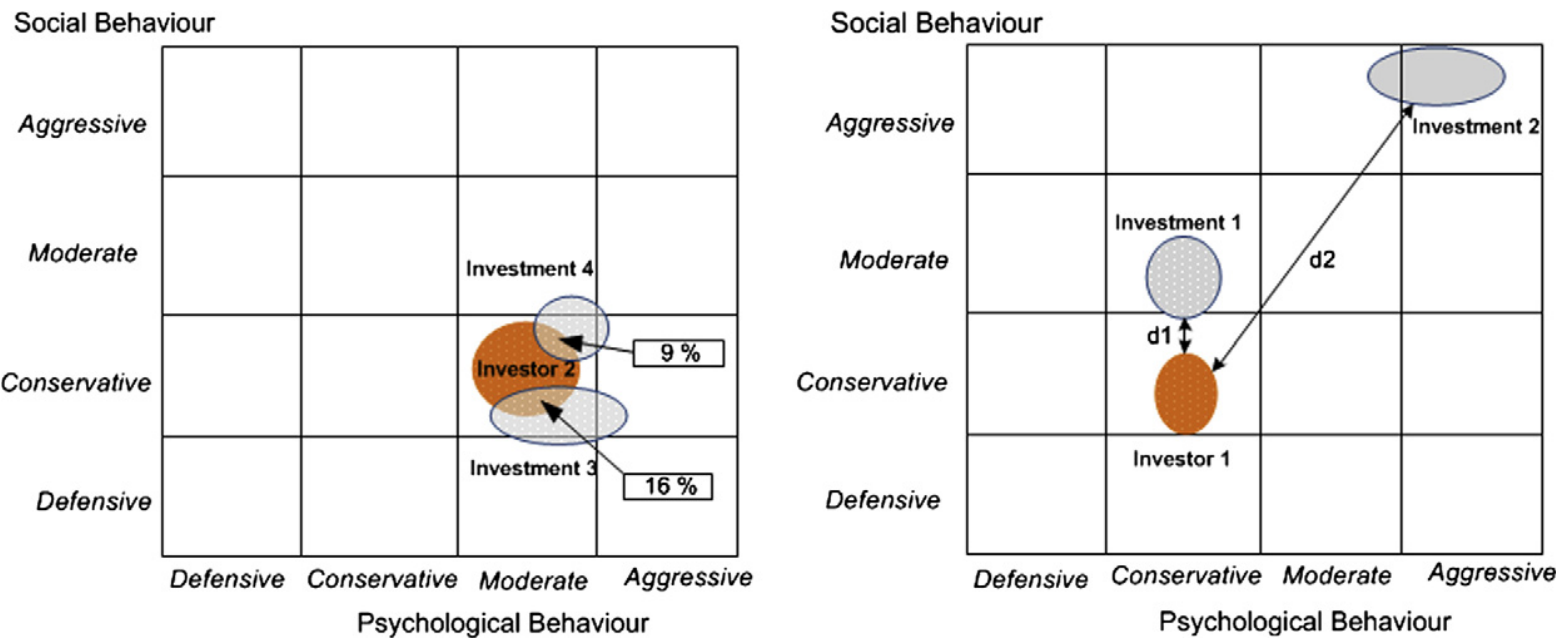

Fig. 9. Different geometrical recommendations with priority.

\subsection{Rich recommendation}

Corporations have been posting financial information on the Web since the mid-1990s. Indeed, the corporate finance and investor relation functions were "early adopters" of Web technology. Use of the Web for financial reporting is now globally pervasive. Furthermore, the ability to acquire, communicate, and disseminate business information is vital for investor and management decision-making. Today's ever-growing amount of information and the diverse formats in reporting business and financial data make collecting and publishing it all a major challenge for global organizations. Until recently, there was no standard format for communicating accounting information. As a result, organizations had to manually assemble it from often-incompatible information systems to prepare financial reports.

To remedy this situation, the international normalization bodies proposed an open and free standard, namely XBRL (eXtensible Business Reporting Language), based on XML (eXtensible Markup Language) and structured in direct compliance with accounting regulations [21]. The use of XML and XBRL may create markets and opportunities that previously did not exist. The eXtensible Markup Language (XML) is a language that defines a set of codes or tags that can be attached to the text to describe its meaning. XBRL is a variant of XML specifically designed to provide the semantics of text associated with business reporting. Both are designed to help achieve the goal of interoperability. In other words, one organization should be able to exchange data and use the information system services provided by another organization independent of the technology platforms that both use.

Finally, thanks to this component PB-ADVISOR will enable the private banker to operate more efficiently and better leverage his core capabilities.

\subsection{Architecture and components of PB-ADVISOR}

Fig. 10 depicts a three-layer scheme that represents PB-ADVISOR architecture along with its main interactions. The two main actors of PB-ADVISOR are the private banker and the expert. The first actor deals with the system and communicates the recommendations to the investor when the process is finished. The second actor, the expert, puts all his experience into the system to refine the recommendations of PB-ADVISOR. Before the system can be used, the financial products must be labeled according to the terms of the financial ontology, and the rules for matching the financial products with the investor's risk profile must be defined.

The overall functionality of the proposed system is based on the following steps:

(1) [Interface (I/F) Layer] In the first step, the private banker interacts with Faceted Classification component to determine the risk preferences and social aspects of the investor(s), as well as the particular characteristics of the investment, such as how much money the investor wants to spend.

(2) [Logic and Persistence Layer] Once the investor has been categorized using the Faceted Classification, the Reasoning Engine extracts the useful information for the investor ontologies that will feed the Fuzzy System, i.e. the information about social and psychological characteristics. The Fuzzy Engine determines the risk profile of the investor, based on the fuzzy set rules defined previously.

(3) [Logic and Persistence Layer] Once the risk profile of the investor has been established, the fuzzy system determines the characteristics of the financial products in terms of fuzzy expressions. 


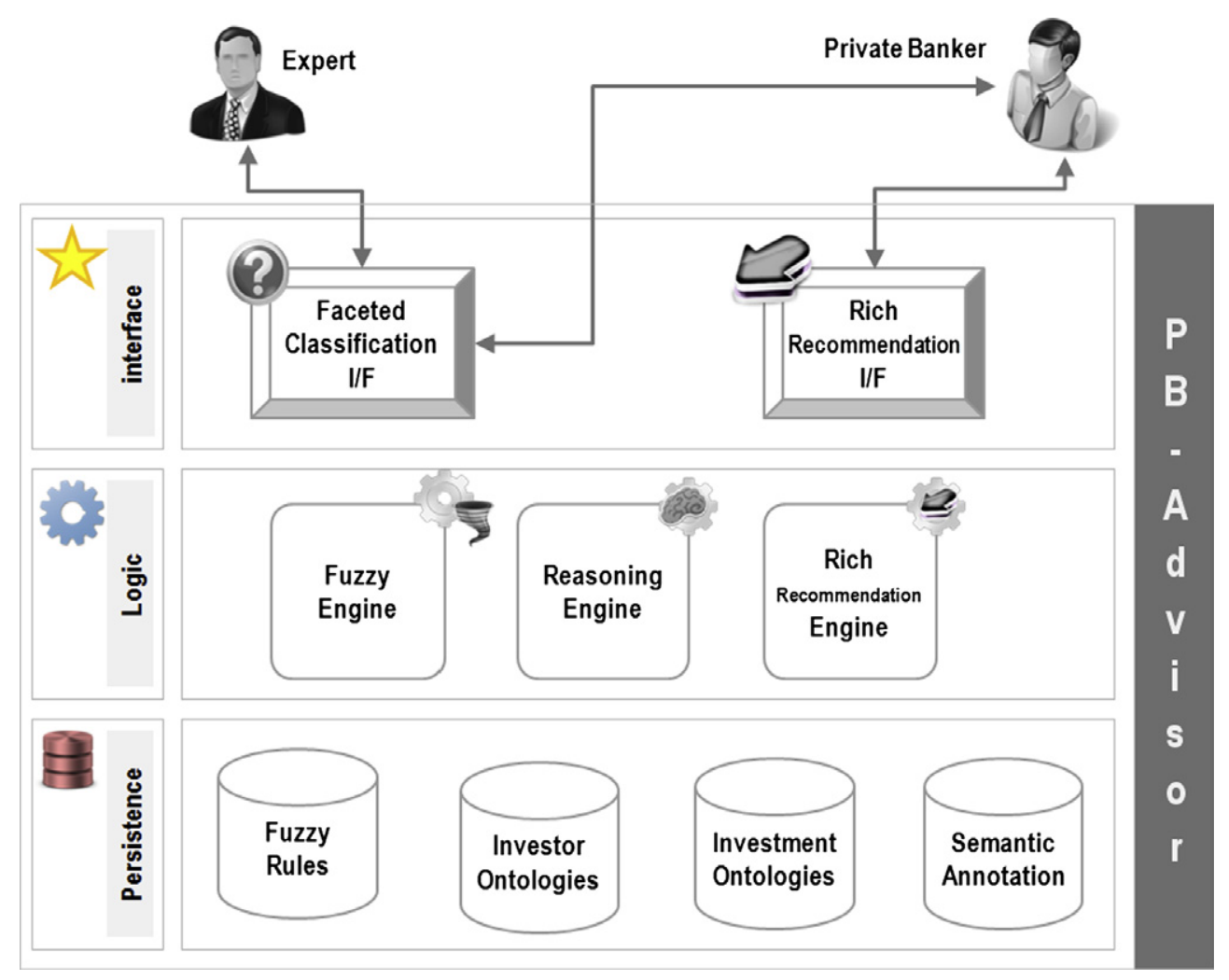

Fig. 10. PB-ADVISOR architecture, components and interactions.

(4) [Logic and Persistence Layer] Based on the fuzzy results, the financial products are selected from the product database by the Reasoning Engine. These products have been previously described and semantically annotated according to the expert's criteria and the financial ontology.

(5) [Logic and Persistence Layer] The system generates a set of portfolios based on the selected products and the characteristics of the investment.

(6) [Logic and Interface (I/F) Layer] The portfolios are rated according to their characteristics and are recommended to the private banker using XBRL format, thereby improving the efficiency, consistency and transparency of these financial recommendations.

Taking into account the layers of PB-ADVISOR, the architecture and components are structured into three layers:

(I) Interface Layer $(I / F)$. The user interface consists of two different components. The Faceted Classification Component interacts with the private banker and the expert in order to determine the profile of the investor and to fine-tune the portfolio investments. Then, the Faceted Classification is performed in order to determine the investor profile and the investment characteristics. Following that, the Reasoning Engine component of the Logic Layer classifies the investor and the investment through the corresponding ontologies.

When the questioning processing is finished, PB-ADVISOR presents a recommendation regarding the most suitable portfolio according to the investor profile through the second component, the Rich Recommendation I/F. The output of the system is encapsulated in XBRL format as it has become a standard means for businesses to communicate over the Internet. Furthermore, the Interface Layer allows for the management of financial products, as well as the definition of the fuzzy sets and fuzzy rules that enable the creation of the investment portfolios. All these components are based on a web interface which is available in a private area of the website developed.

(II) Business Logic Layer. The business logic layer consists of three components:the Fuzzy Engine, the Reasoning Engine and the Rich Recommendation Engine. The Fuzzy Engine evaluates the defined fuzzy rules in order to determine the investor's profile. When the investment advisor represents his knowledge through the Interface Layer, the Fuzzy Engine validates the fuzzy sets and the fuzzy rules. Afterwards, the semantic information relative to the characteristics of the investors and the investment products is retrieved by the Reasoning Engine. This component has been developed based on the Jena framework. Jena provides Resource Description Framework (RDF) and Ontology Web Language (OWL) support as well as an API for writing and extracting data from OWL descriptions. It is an open source framework 
that complies with the requirements of the platform proposed in this paper, and furthermore, the research team had experience with this framework.

Finally, the Rich Recommendation Engine encapsulates the products' recommendations following the XBRL syntax.

(III) Persistence Layer. This layer is divided into four components : Investor Ontologies, Fuzzy Rules, Investment Ontologies and Semantic Annotation. The first component stores the investor profile and categorization using the ontologies defined in OWL. The second component stores the fuzzy sets and the fuzzy rules in a database. The system's database also stores the relationships between the fuzzy rules and the characteristics represented by the ontologies. The third component stores the knowledge of the investment products, with the relations between the investment products and the investment profiles. Finally, all the characteristics of the investors and the financial products are defined by means of OWL ontologies using the Semantic Annotation component.

\section{Numerical example of PB-ADVISOR}

For a better understanding of the proposal, a numerical example has been included in this section. The private banker introduced the characteristic of the investor, John Doe, in PB-ADVISOR through the Faceted Classification Interface. Afterwards, the Reasoning Engine and the Fuzzy Engine determined the following SB and PB sets:

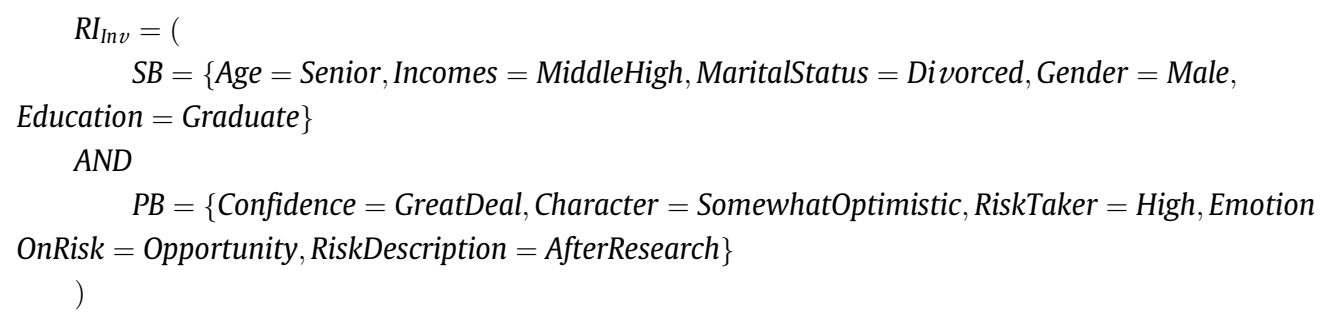

Based on the fuzzy rules defined by the expert and the linguistic adverbs, the resulting categorization of the investor is:

(1) The investor John Doe is Somewhat Psychologically-Aggressive and Fairly Socially-Moderate

On translating this rule to the business portfolio analysis matrix, the representation included in Fig. 11 is obtained:

The three investments selected for this numerical simulation are Currency Deposit, Startup Investment and Solar Farms, which are labeled Investment A, Investment B and Investment C.

Based on the fuzzy rules defined by the expert and the linguistic adverbs, the resulting categorization of investments $A$ and $\mathrm{B}$ is:

(2) Investment A is Highly Psychologically-Moderate and fairly Socially-Moderate

(3) Investment B is Somewhat Psychologically-Aggressive and Somewhat Socially-Conservative

(4) Investment $\mathrm{C}$ is Highly Psychologically-Aggressive and fairly Socially-Moderate

The translation of these fuzzy sets and rules to the business portfolio analysis matrix is shown in Fig. 12:

Next, the expert has fine-tuned a set of values for the weights used in Eq. (10), by which the following FDs are obtained for the investor and the investments by applying the equations mentioned in the previous section:

- $\mathrm{FD}_{\text {investor }}=(0.48,0.39)$.

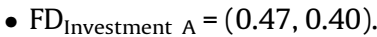

- $\mathrm{FD}_{\text {Investment } \mathrm{B}}=(0.19,0.40)$.

- $\mathrm{FD}_{\text {Investment } \mathrm{C}}=(0.17,0.55)$.

Finally, to find the recommendation of product portfolio that best fits the characteristics of the investor John Doe, four ellipses will be plotted. The first ellipse represents, taking into account the $\mathrm{FD}_{\text {investor }}$, the area of influence of the investor.

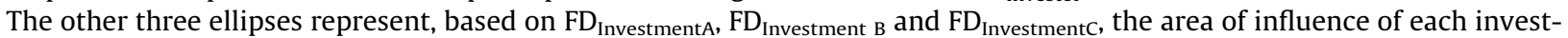
ment. In Fig. 13, these ellipses and the overlapped areas for this example are shown.

In this example the overlapped area of investment $B$ over the area of the investor area is larger than the overlapped area of investment $A$, so the system will propose the first as the best option for the investor John Doe. Investment $C$ has no overlapped area; thus, the system returns it as the last option. By default, PB-ADVISOR shows the private banker the first two investments as its recommendation. To increase interoperability, this recommendation is encapsulated using XBRL. 


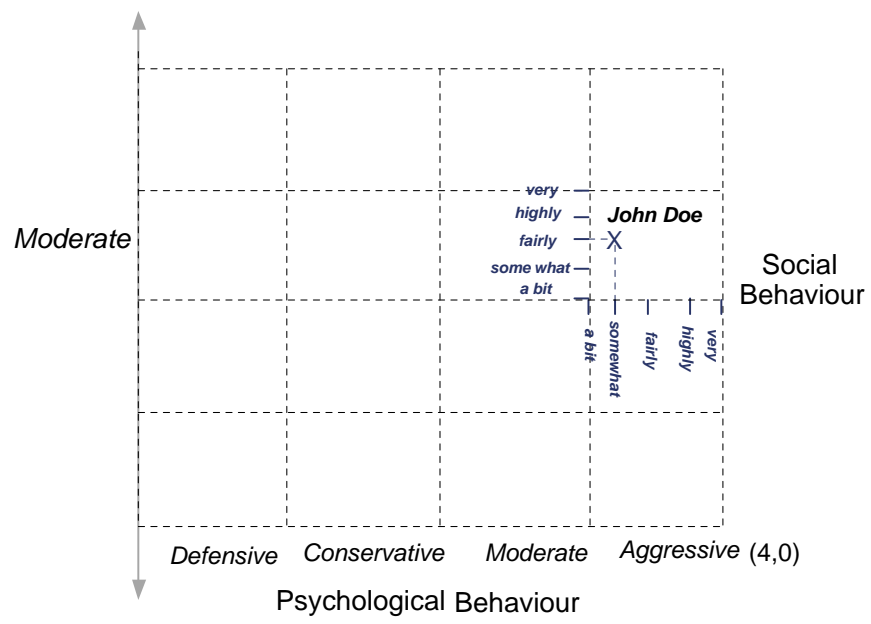

Fig. 11. Matrix representation of the investor John Doe.

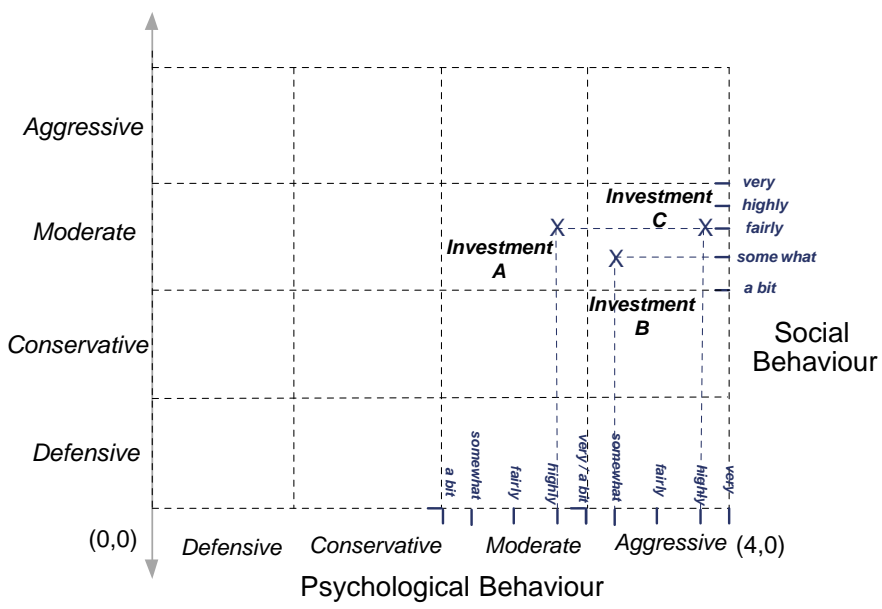

Fig. 12. Matrix representation of investments A and B.

\section{Empirical evaluation process in PB-ADVISOR}

The following section describes the empirical evaluation of the proposal. The final aim of this study is to determine whether PB-ADVISOR serves as a valid recommendation system in a controlled environment.

\subsection{Research design}

To check the validity of the proposed recommendation system an experimental phase was carried out in this research. This experiment had to take into account expert's criteria and the customer profile according to the investor and financial ontologies. The evaluation was composed of two phases. The aim of Phase 1 was to provide a set of test cases in order to execute Phase 2. Firstly, the private banker interacts with PB-ADVISOR, through the Faceted Classification Interface defined for the categorization of the investors. Secondly, a set of experts analyze a set of investments offered by Spanish financial entities in order to categorize them according to the psychological and social risk profile of their possible investors. Both investor and investment categorizations are processed by PB-ADVISOR in Phase 2. Fig. 14 summarizes the phases of the research design.

In detail, Phase 1 consists of two steps related with the inputs of PB-ADVISOR. First, 30 investors were selected to participate in this experiment. The private banker interacts with PB-ADVISOR through the Faceted Classification Interface to determine the psychological and social profiles of risk aversion for each investor (as described in Section 3). The estimated investment of each investor is 1 million euros. The investor profile defined through this process is then used in Phase 2 to provide the most suitable investment recommendations for him. Secondly, 30 products were selected and categorized 


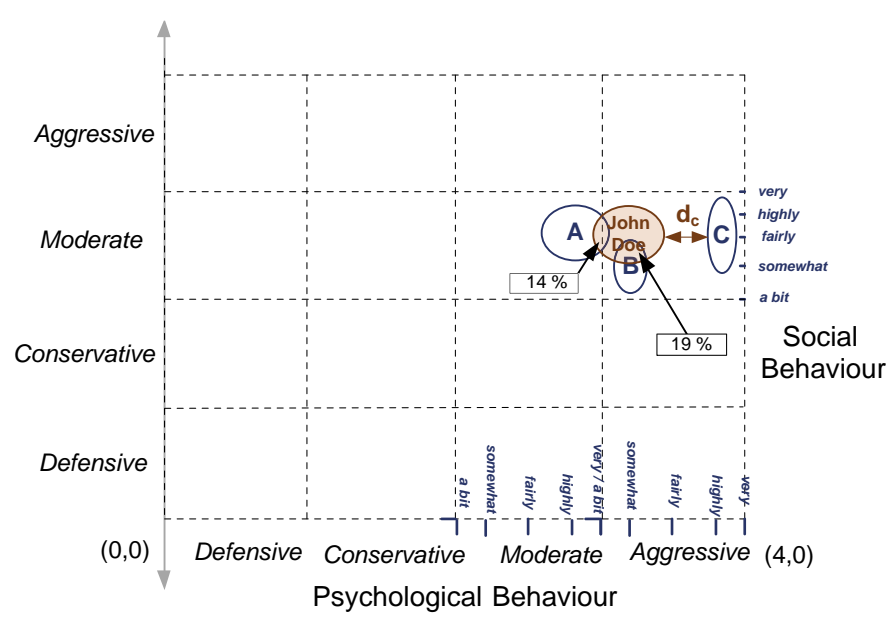

Fig. 13. Geometrical recommendation with priority for investments A and B.

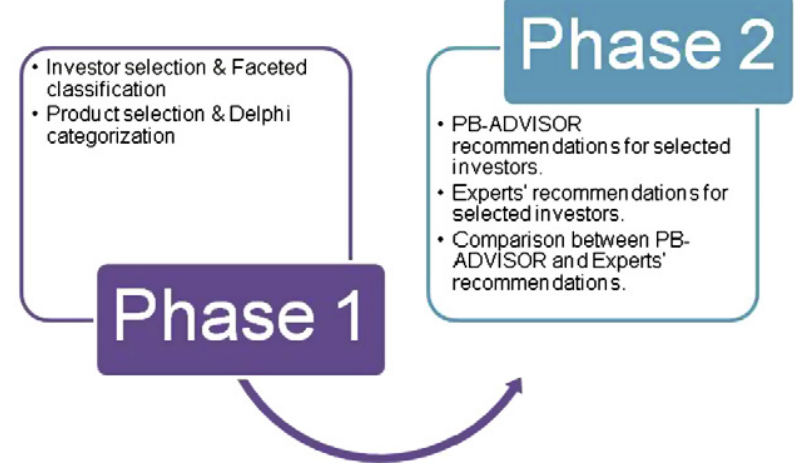

Fig. 14. Research design summary.

according to the different social and psychological features of the potential investor. This classification was carried out by the six experts using the Delphi method. Each expert assigned each product to a square of a grid that represented the most appropriate social and psychological profiles for the product. Ten kinds of financial products for providing recommendations were selected: (1) Prime Retail Real Estate, (2) Land, (3) Mall Retail Real Estate, (4) Building Real Estate, (5) Fixed Term Deposits, (6) Structured Deposits, (7) Currency Deposits, (8) Bonds, (9) Startup Investments, (10) Solar Farms. A financial expert selected 3 real products of each kind. The products are identified by a numerical category (between 1 and 10) and a sequential number (between 1 and 3), e.g. product 10.3 is the third product of the solar farms category.

Once all of the investors and the financial products had been labeled, Phase 2 began. At this moment, the private banker, through the faceted classification, describes the profile of the investor (focusing on social and psychological characteristics). PB-ADVISOR obtains a set of two recommendations for each investor using the matching process described in Section 3. Simultaneously, based on the same investor classification, the six experts (financial advisors) made a recommendation of two products to be compared with the results of PB-ADVISOR. Agreement among the experts for the recommendation was achieved using the Focus Group method.

Therefore, and to summarize, the private banker would have four different recommendations for each investor, two provided by the expert and other two by PB-ADVISOR. Next, in order to determine the accuracy of the PB-ADVISOR results, Precision and Recall and F1 measures were used to measure the degree of relevance of the recommendations provided by PB-ADVISOR with respect to the experts' recommendations. Recall and precision measures reflect the different aspects of annotation performance.

The next subsection describes the population sample used in this evaluation and the results obtained in each phase.

\subsection{Sample}

The sample used to implement the evaluation of this research is divided into two different sets: the investors and the experts. 
In the first set, 30 individuals took part in the experiment (14 men and 16 women with an average age of 35.1). These investors were master's degree students and faculty at Universidad Carlos III de Madrid, who had different risk profiles according to their social and psychological characteristics. Secondly, to provide recommendations and to categorize the investments, a group of six expert investment advisors was used, with an average of 9 years' experience in the Spanish private banking sector.

The next section details the main results obtained for Phases 1 and 2 of the evaluation process.

\subsection{Results: Phase 1}

As introduced in the previous section, in Phase 1 two different categorizations were created: (1) the investor by the private banker and (2) the investment by six experts.

In the second, the Delphi method was used to categorize the different recommendations taking into account the decisions of the six experts. To achieve this, first, Kendall's coefficient of concordance ( $W$ or Kendall's $W$ ) was computed to measure the level of agreement among the experts. The six experts obtained a coefficient of agreement of $W=0.6732$. Finally, agreement between experts was achieved by applying the Delphi method. The final classification of the products selected for the evaluation is depicted in Fig. 15. Furthermore, each quadrant has a sequential number, between 1 and 16 assigned, for identification.

The investments and investor categories were thus used as the inputs of Phase 2 in PB-ADVISOR in order to provide the most suitable investment recommendations for each investor.

\subsection{Results: Phase 2}

Two kinds of recommendations are obtained as the output of this phase. The first is given by the system and the other by the experts. Each of them recommends two products, depending on the investor profile.

During this phase, PB-ADVISOR provides a set of two recommendations by the private banker for the investors identified in Phase 1. At the same time, experts also provide a set of investments for the investors in order to compare the results with PB-ADVISOR. The expert recommendations are carried out by a group of experts using the Focus Group method (which allows agreement among the experts' points of view). The estimated investment for each investor is 1 million euros and both PB-ADVISOR and the experts recommend the most suitable products in the portfolio under this condition.

Table 3 shows the two recommendations provided by PB-ADVISOR for each investor, and the corresponding recommendation of the experts.

Before considering the accuracy of the system, the coverage measure should be mentioned. This measure is related to the number of products the system recommends with respect to the total of available products in the system. Low values of coverage imply that the system only recommends a low number of products among the total available. Private bankers usually have a great deal of products available, but sometimes they do not recommend a number of products for different reasons (for example, lack of confidence in these products, the market situation, or the expert's personal point of view). In the same way, the intelligent recommenders systems could avoid recommendation of some products because of the particular characteristics of the decision rules on which the decision is based. Considering the two recommendations of PB-ADVISOR, the

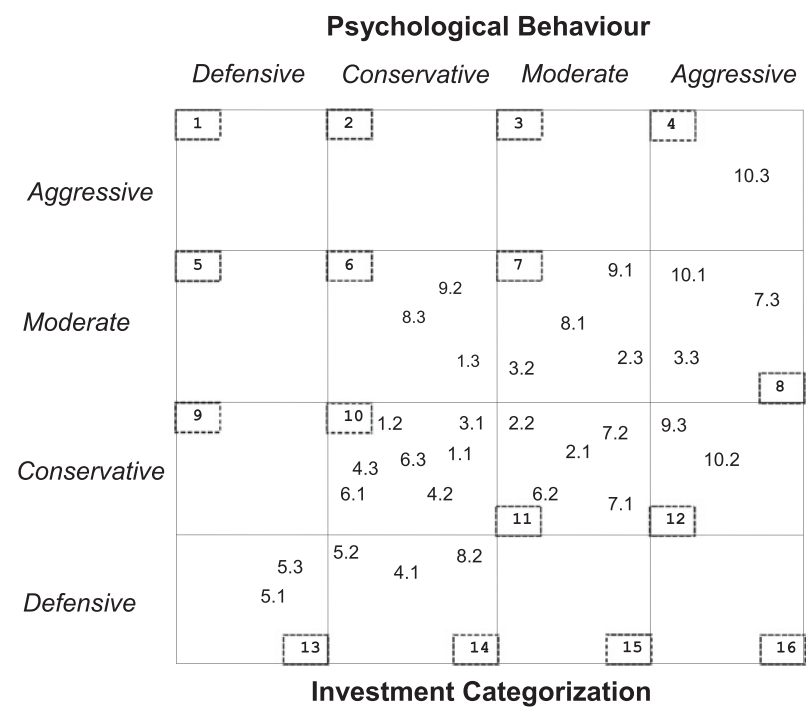

Fig. 15. Product categorization using the Delphi method. 
Table 3

PB-ADVISOR recommendations vs. expert recommendations.

\begin{tabular}{|c|c|c|c|c|}
\hline Investor & $\begin{array}{l}\text { PB-ADVISOR } \\
\text { Recommendation } 1\end{array}$ & $\begin{array}{l}\text { PB-ADVISOR } \\
\text { Recommendation } 2\end{array}$ & $\begin{array}{l}\text { Expert } \\
\text { Recommendation } 1\end{array}$ & $\begin{array}{l}\text { Expert } \\
\text { Recommendation } 2\end{array}$ \\
\hline 1 & 6.1 & 4.2 & 5.2 & 4.1 \\
\hline 2 & 2.1 & 7.2 & 7.1 & 7.2 \\
\hline 3 & 2.3 & 3.3 & 2.3 & 8.1 \\
\hline 4 & 3.1 & 2.2 & 3.1 & 1.1 \\
\hline 5 & 4.2 & 1.1 & 3.1 & 6.2 \\
\hline 6 & 10.2 & 9.3 & 9.3 & 10.2 \\
\hline 7 & 5.3 & 5.1 & 5.2 & 5.1 \\
\hline 8 & 9.2 & 8.3 & 9.2 & 8.3 \\
\hline 9 & 1.2 & 3.1 & 1.2 & 1.1 \\
\hline 10 & 7.1 & 6.2 & 7.1 & 6.2 \\
\hline 11 & 7.2 & 2.1 & 9.3 & 10.2 \\
\hline 12 & 3.3 & 7.3 & 3.3 & 10.1 \\
\hline 13 & 1.1 & 3.1 & 1.1 & 2.2 \\
\hline 14 & 4.1 & 5.2 & 4.1 & 6.1 \\
\hline 15 & 8.2 & 4.1 & 8.2 & 4.2 \\
\hline 16 & 1.3 & 3.2 & 1.3 & 3.2 \\
\hline 17 & 4.2 & 6.3 & 4.2 & 8.2 \\
\hline 18 & 7.3 & 10.1 & 7.3 & 10.1 \\
\hline 19 & 10.2 & 9.3 & 9.3 & 7.2 \\
\hline 20 & 6.1 & 4.2 & 6.1 & 5.2 \\
\hline 21 & 3.2 & 1.3 & 2.2 & 3.1 \\
\hline 22 & 9.1 & 2.3 & 8.1 & 2.3 \\
\hline 23 & 2.1 & 7.1 & 9.3 & 7.1 \\
\hline 24 & 3.1 & 1.1 & 1.3 & 1.1 \\
\hline 25 & 2.2 & 2.1 & 2.2 & 3.2 \\
\hline 26 & 10.3 & 10.1 & 10.3 & 7.3 \\
\hline 27 & 9.3 & 10.2 & 9.3 & 3.3 \\
\hline 28 & 1.2 & 3.1 & 1.2 & 1.3 \\
\hline 29 & 8.2 & 4.1 & 5.2 & 4.1 \\
\hline 30 & 5.2 & 4.1 & 5.2 & 5.3 \\
\hline
\end{tabular}

coverage of the system is $90 \%$. According to [38] the coverage should be measured in combination with accuracy. In the following step, the accuracy analysis was performed.

In order to determine the accuracy of the PB-ADVISOR results, Precision and Recall and F1 measures were used to measure the degree of relevance of the recommendations provided by PB-ADVISOR with respect to the experts' recommendation. The following results describe several perspectives regarding the implementation of this analysis. In this first analysis, the products recommended by the experts were considered correct recommendations. The overall result establishes that if the first or second recommendation of PB-ADVISOR coincides with those recommended in the same order by the experts it is then considered a correct investment. Next, the second analysis determines that if the first product recommended by PBADVISOR coincides with the first recommendation of the experts it is then considered a correct investment. Finally, the last analysis establishes that if the second product recommended by PB-ADVISOR coincides with the second recommendation of the experts it is then considered a correct investment.

Table 4 shows the values obtained in the first Precision and Recall and F1 study. Precision, Recall and F1 values are the same because the number of correct recommendations is the same as the number of recommendations offered by PBADVISOR.

For the second analysis, each recommendation is considered correct when PB-ADVISOR and the experts provided the same order for the two products. Table 5 shows Precision and Recall results for each PB-ADVISOR recommendation with respect to the two products offered by the expert. In this particular case, it is important to note that Precision and Recall scores are different, since correct investments are not equal to suggested investments.

The above results show the values of Precision and Recall with respect to the expert recommendations. However the precision of PB-ADVISOR can be measured with respect to the products of the categories recommended by the expert. For example, if the expert proposes investments from the category Conservative-Conservative (cell 10), the Precision and Recall is

Table 4

Precision and recall analysis for product recommendations.

\begin{tabular}{ll}
\hline & Precision, Recall and F1 \\
\hline Overall PB-ADVISOR Recommendations vs. Overall Expert Recommendations & 0.467 \\
First PB-ADVISOR Recommendation vs. First Expert Recommendation & 0.600 \\
Second PB-ADVISOR Recommendation vs. Second Expert Recommendation & 0.333
\end{tabular}


Table 5

Precision and recall values for both expert recommendation.

\begin{tabular}{llll}
\hline & Precision & Recall & F1 \\
\hline $\begin{array}{c}\text { Both PB-ADVISOR Recommendations vs. } \\
\text { Both Expert Recommendations }\end{array}$ & 0.517 & 0.258 & 0.344 \\
\hline
\end{tabular}

Table 6

Precision and recall results for investments with correct categorization.

\begin{tabular}{|c|c|c|c|}
\hline & Precision & Recall & F1 \\
\hline PB-ADVISOR Cell Recommendation vs. Investments in the correct Cell & 0.566 & 0.147 & 0.233 \\
\hline First PB-ADVISOR Cell Recommendation vs. Investments in the Cell of First Expert Recommendation & 0.766 & 0.233 & 0.357 \\
\hline Second PB-ADVISOR Cell Recommendation vs. Investments in the Cell of Second Expert Recommendation & 0.366 & 0.108 & 0.168 \\
\hline
\end{tabular}

Table 7

Precision and recall and F1 results for recommendations in categories proposed by the experts.

\begin{tabular}{llll}
\hline & Precision & Recall & F1 \\
\hline Both PB-ADVISOR Cell Recommendations vs. Any Expert Cell Recommendations & 0.833 & 0.229 & 0.359 \\
First PB-ADVISOR Cell Recommendation vs. Any Expert Cell Recommendations & 0.866 & 0.260 & 0.400 \\
Second PB-ADVISOR Cell Recommendation vs. Any Expert Cell Recommendations & 0.800 & 0.237 \\
\hline
\end{tabular}

calculated considering all the products categorized as Conservative-Conservative to be correct investments. Table 6 shows the results obtained for the described Precision and Recall measures considering the results for each investment.

The values of Precision and Recall are the mean of the precision and recall values for each recommendation of PB-ADVISOR. Table 7 presents the results obtained if the set of correct products is extended to all products categorized in both categories determined by the expert for each investment window.

\section{Discussion}

The goal of the designed evaluation is to check the validity of the proposed recommendation system. The experiments carried out have taken into account expert criteria and the customer profile according to the investor and financial ontologies. To evaluate the performance of the system, Precision and Recall and F1 metrics were used to measure the degree of relevance of the recommendations provided by PB-ADVISOR with respect to the experts' recommendation.

On analyzing the results presented in Section 5.2, and taking into account the order of both recommendations of the system and the experts, the Precision, Recall and F1 overall result is $46.7 \%$ (Table 4). However, if we only focus on the first recommendation of PB-ADVISOR, i.e. the system and the experts give the same product as first option, the performance increases up to $60 \%$. Focusing on the second recommendation, $33.3 \%$ of products offered by PB-ADVISOR are the same as those recommended by the experts. Moreover, in the second test performed, if the system recommendation (first or second) appears in any of the experts' recommendation, the analysis shows $51.7 \%$ for Precision, $25.8 \%$ for Recall and $34.4 \%$ for F1 (Table 5). These results may be regarded as satisfactory and at the end of this section they will be compared with those from other proposals.

In the last two analyses, the precision of the system is measured with respect to the products of the categories recommended by the expert, i.e. the cells where the products recommended by the expert and the system are located. If the order of the recommendations is taken into account, the Precision value increases up to $56.6 \%$ for both products and up to $76.6 \%$ for accuracy if we only look at the first recommendation (Table 6). Finally, if the system recommendation (first or second) appears in any of the expert's recommendations, the precision value is $83.3 \%$, and if only the first recommendation of the system coincides with any of expert's products, the precision value is $86.6 \%$.

Furthermore, and going a step further, it is of interest to compare the performance of PB-ADVISOR with other recommender systems. The use of Precision and Recall metrics for analyzing the effectiveness of recommender systems has been proven by several authors in different domains [26].

Garcia-Crespo et al. [30] present a recommendation system for individual investors. This previous system does not incorporate faceted search nor the rich recommendations described, and the rules are oriented towards the individual investment of small investors. The best approach for this system achieves 32\% for precision and 32\% for recall.

Zanker and Jessenitschnig [79], for example, define a recommender system for suggesting useful and interesting items to users in order to increase user satisfaction and online conversion rates in e-commerce environments. In this research, the authors compare the performance of different recommendation strategies computing the accuracy of the recommendations 
Table 8

Comparison with other recommender systems in terms of Recall and F1.

\begin{tabular}{lll}
\hline Recommendation & Recall (\%) & F1 \\
\hline PB-ADVISOR vs. Expert (Table 4) & 46.70 & 0.467 \\
PB-ADVISOR vs. Both Experts (Table 5) & 51.70 & 0.258 \\
PB-ADVISOR vs. Correct cell (Table 6) & 14.70 & 0.233 \\
PB-ADVISOR vs. Any expert cell (Table 7) & 22.90 & 0.359 \\
Portfolio [30] & 32.00 & 0.320 \\
Conversion rates[79] & 27.58 & 0.138 \\
E-Commerce [80] & 9.12 & 0.131 \\
Consumer Behaviour Prediction[71] & 91.00 & 0.968 \\
Movies[14] & 29.00 & 0.450 \\
\hline
\end{tabular}

by means of the precision, recall and F1 metrics. In this research, the best results obtained within the experiments performed are $9.21 \%$ for precision, $27.58 \%$ for recall and $13.81 \%$ for $\mathrm{F} 1$.

In this context of e-commerce, Zanker et al. [80], formalize the different variants of a constraint-based recommendation problem based on consistency and compare the performance of different constraint-based recommendation mechanisms in offline experiments on historical data using Precision and Recall metrics. In this case, the Precision, Recall and F1 values obtained by the authors are $23.80 \%, 9.12 \%$ and $13.09 \%$, respectively.

Garćia et al. [28], propose a semantic hotel recommendation expert system, based on the consumer's experience of recommendations provided by the system. Precision, Recall and F1 metrics measure the degree of relevance of the recommendations of the fuzzy system compared with the opinion of experts in the domain. In the two tests performed, the system recommendations are on the same level as the experts, with $58 \%$ and $76 \%$ of the system star recommendations coinciding with those of the experts.

Finally, Wang and Cheng-Ting [71], propose a recommender system for predicting consumers' purchase behaviour in Taiwan electronic commerce. To evaluate the performance of information retrieval, the authors use precision, recall and F1 measures. In this case, the best results obtained in the three experiments are $94 \%$ for precision and $91 \%$ for recall.

Up to now, the obtained results with Precision, Recall and F1 measures have been compared. Cremonesi et al. [14] take into account only the recall and F1 measures for seven different algorithms in the domain of movies. The best results shown in said work are $29 \%$ for precision and $45 \%$ for $\mathrm{F} 1$. We found that in our main approach, the recall value is higher ( $46.7 \%$ vs. $29 \%)$.

Table 8 summarizes the results of PB-ADVISOR with respect to other recommender systems. Despite the fact that the domains are not comparable, we found that PB-ADVISOR results are quite acceptable when comparing them with other recommender approaches. In particular, when compared with [30], the increase in F1 by $14 \%$ highlights the benefits of the proposed system. This increase is more than patent when compared with [79] (PB-ADVISOR improves by $160 \%$ F1 figures) and [80], (174\%). However, PB-ADVISOR, due to the intrinsic complexity of the functional scenario is below the achievements of [71] (62\%) and [14] (20\%), where recommendations are more accurate.

With respect to the coverage metric, this measure is not employed in all of the studies. For this reason it is difficult to establish clear conclusions in this sense. The coverage of PB-ADVISOR is $90 \%$ with respect to the $77.8 \%$ of [30] (which have comparable domains) reflecting the improvements of PB-ADVISOR.

There is a large variety of recommendations with acceptable accuracy results making PB-ADVISOR a powerful tool for private bankers. Therefore, based on Precision, Recall and F1 metrics, the results obtained from PB-ADVISOR are within the expected behaviour for recommendation systems. Hence, and taking into account this asseveration, PB-ADVISOR is capable of offering a set of recommendations that will be accepted most of the time, based on the investor profile and the product portfolio described by the experts.

\section{Conclusions and future work}

The number of investment products and the complexity of today's markets have given rise to a need for new tools for private bankers. In fact, the number of products offered is ever-growing and in constant flux. New tools for easing the work of private bankers who advise their clients on a daily basis about how to invest their money are, therefore, a necessity.

This article has presented PB-ADVISOR a multi-investment recommendation system based on semantic technologies and fuzzy logic. By combining both technologies with faceted searching, the system provides private bankers with tailor-made recommendations for their clients, based on those clients' characteristics. The semantic characterization of the investments and their characteristics enable the private banker to recommend a wide spectrum of products with very diverse characteristics. Characteristics of investors are also semantically represented. The relations between investments and investors are defined by means of fuzzy rules that are able to represent expert advisor knowledge. In this way, the system is able to recommend new products by including and annotating their characteristics in the knowledge base. The results obtained have shown that the system is able to offer recommendations comparable with those from experts in the field.

On comparing the experimentation results with other recommender approaches, the precision of PB-ADVISOR is remarkable, taking into account that, due to the great variety of products and characteristics, it is common for several experts to 
provide different recommendations for the same client in the same context. The precision of PB-ADVISOR with the investment categories is near $83 \%$. This means that most of the times PB-ADVISOR provides a recommendation of the same category as that provided by the experts. How these results can be improved is part of future research.

As previously stated, the characteristics of the private banking area and the current economic situation make advisement a difficult process. As in many other recommending areas, the point of view of experts is the main source of knowledge. Further research should be focused on the collaboration among experts on the characterization of investments and the definition of the fuzzy rules that guide the recommendation process. The approach of Alonso et al. [3], providing a consensus support system, could be an interesting starting-point for achieving agreement between experts in the definition of the rules that guide PB-Advisor. Also the inclusion of ratings [24] in the recommendations could be applied to improve the proposed system. Finally, in addition to the new features, the enlargement of the experimental samples with more population, experts and products will be addressed in future work.

\section{Acknowledgements}

This work is supported by the Spanish Ministry of Industry, Tourism, and Commerce under the projects SONAR2 (TSI020100-2008-665) and the Spanish Ministry of Science and Innovation under the project "Financial linked open data reasoning and management for web science" (TIN2011-27405).

\section{References}

[1] H.P. Adkisson, Use of Faceted Classification, 2009. <http://www.webdesignpractices.com/navigation/facets.htm> (accessed 02.04.11).

[2] H. Akerlund, Fading customer relationships in professional services, Manage. Serv. Qual. 15 (2) (2005) 156-171.

[3] S. Alonso, E. Herrera-Viedma, F. Chiclana, F. Herrera, A web based consensus support system for group decision making problems and incomplete preferences, Inf. Sci. 180 (23) (2010) 4477-4495.

[4] G.K. Al-Sharrah, I. Alatiqi, A. Elkamel, Planning an integrated petrochemical business portfolio for long-range financial stability, Ind. Eng. Chem. Res. 41 (11) (2002) 2798-2804.

[5] G. Al-Sharrah, A. Elkamel, A. Almanssoor, Sustainability indicators for decision-making and optimisation in the process industry: the case of the petrochemical industry, Chem. Eng. Sci. 65 (4) (2010) 1452-1461.

[6] J.M.T. Balmer, S. Stotvig, Corporate identity and private banking, Int. J. Bank Mark. 15 (5) (1997) 169-184.

[7] J. Bicheno, Exploring productivity accounting for management and strategy in manufacturing and services, Int. J. Oper. Prod. Manage. 9 (5) (1989) 5668

[8] U. Birchler, T.D. Cocca, D. Ettlin, The International Private Banking Study 2009, Swiss Banking Institute, 2009.

[9] M.A. Boyacioglu, Y. Kara, O.K. Baykan, Predicting bank financial failures using neural networks, support vector machines and multivariate statistical methods: a comparative analysis in the sample of savings deposit insurance fund (SDIF) transferred banks in Turkey, Expert Syst. Appl. 36 (2) (2009) 3355-3366. Part 2 .

[10] V. Broughton, The need for a faceted classification as the basis of all methods of information retrieval, Aslib Proceedings 58 (1/2) (2006) 49-72.

[11] Q. Cao, M.E. Parry, Neural network earning per share forecasting models: a comparison of backward propagation and genetic algorithm, Decis. Support Syst. 47 (1) (2009) 32-41.

[12] P.C. Chang, C.H. Liu, J.L. Lin, C.Y. Fan, C.S. P Ng, A neural network with a case based dynamic window for stock trading prediction, Expert Syst. Appl. 36 (3) (2009) 6889-6898.

[13] J.S. Chen, J.L. Hou, S.M. Wua, Y.W. Chang-Chien, Constructing investment strategy portfolios by combination genetic algorithms, Expert Syst. Appl. 36 (2) (2009) 3824-3828.

[14] P. Cremonesi, F. Garzotto, S. Negro, A.V. Papadopoulos, R. Turrin, Looking for "Good" recommendations: a comparative evaluation of recommender systems, in: Human-Computer Interaction - INTERACT 2011, Proceedings of 13th IFIP TC13 Conference on Human-Computer Interaction, 2011, pp. $152-168$

[15] E. Cox, Fuzzy logic and the measures of certainty in eCommerce expert systems, PC AI 15 (3) (2001) 16-22.

[16] P. Da Silva Borges, A Model of Strategy Games based on the Paradigm of the Iterated Prisoner's Dilemma Employing Fuzzy Sets, PhD thesis, Universidade Federal de Santa Catarina, Production and Systems Engineering, 1996.

[17] F.R. David, Strategic Management, Prentice-Hall, Upper Saddle River, NJ, 2001.

[18] I. Doole, R. Lowe, International Marketing Strategy: Analysis, Development and Implementation, Cengage Learning EMEA, London, 2008

[19] F. Eshragh, E.H. Mamdani, A general approach to linguistic approximation, Int. J. Man Mach. Stud. 11 (4) (1979) 501-519.

[20] A. Fernandez, S. Gomez, Portfolio selection using neural networks, Comp. Oper. Res. 34 (4) (2007) 1177-1191.

[21] V. Florescu, C.G. Tudor, The optimization of the internal and external reporting in financial accounting: adopting XBRL international standard, Ann. Univ. Apulen. Ser. Econ. 1 (11) (2009) 1-12.

[22] P. Foehn, T. Bamert, Private banking - den Snob-Appeal pflegen, Die Schweiz. Bank 23 (12) (2002) 29-30.

[23] P. Foehn, Client valuation in private banking: results of a case study in Switzerland, Manage. Serv. Qual. 14 (2/3) (2004) 195-204

[24] F. Fouss, Y. Achbany, M. Saerens, A probabilistic reputation model based on transaction ratings, Inf. Sci. 180 (11) (2010) $2095-2123$.

[25] F.D. Freitas, A.F. De Souza, A.R. de Almeida, Prediction-based portfolio optimization model using neural networks, Neurocomputing 72 (10-12) (2009) $2155-2170$

[26] A. García-Crespo, R. Colomo-Palacios, J.M. Gómez-Berbís, B. Ruiz-Mezcua, SEMO: a framework for customer social networks analysis based on semantics, J. Inf. Technol. 25 (2) (2010) 178-188.

[27] A. García-Crespo, R. Colomo-Palacios, J.M. Gómez-Berbís, F. García-Sánchez, SOLAR: social link advanced recommendation system, Future Gener. Comput. Syst. 26 (3) (2010) 374-380.

[28] A. García-Crespo, J.L. López-Cuadrado, R. Colomo-Palacios, I. González-Carrasco, B. Ruiz-Mezcua, Sem-Fit: a semantic based expert system to provide recommendations in the tourism domain, Expert Syst. Appl. 38 (10) (2011) 13310-13319.

[29] A. García-Crespo, J.M. Gómez-Berbís, R. Colomo-Palacios, F. Garćí-Sánchez, Digital libraries and web 3.0. The CallimachusDL approach, Comp. Human Behav. 27 (4) (2011) 1424-1430.

[30] A. García-Crespo, J.L. López-Cuadrado, I. González-Carrasco, R. Colomo-Palacios, B. Ruiz-Mezcua, SINVLIO: using semantics and fuzzy logic to provide individual investment portfolio recommendations, Knowl. Based Syst. 27 (1) (2012) 103-118.

[31] A. Ghazinoorya, A.E. Zadehb, A.S. Kheirkhahb, Application of fuzzy calculations for improving portfolio matrices, Inf. Sci. 180 (9) (2010) $1582-1590$.

[32] M. Giess, C. McMahon, I. Booker, D. Stewart, Application of faceted classification in the support of manufacturing process selection, Proc. Inst. Mech. Eng. Part B: J. Eng Manuf. 223 (6) (2009) 597-608.

[33] J.E. Grable, Risk tolerance, in: J.J. Xiao (Ed.), Handbook of Consumer Finance Research, Springer, New York, 2008, pp. 3-19. 
[34] J.E. Grable, R.H. Lytton, Financial risk tolerance revisited: the development of a risk assessment instrument, Finan. Serv. Rev. 8 (3) (1999) $163-181$.

[35] J.E. Grable, R.H. Lytton, The development of a risk assessment instrument: a follow-up study, Finan. Serv. Rev. 12 (3) (2003) $257-274$.

[36] P. Gupta, M.K. Mehlawat, A. Saxena, A hybrid approach to asset allocation with simultaneous consideration of suitability and optimality, Inf. Sci. 180 (11) (2010) 2264-2285.

[37] W.J. Gutjahr, S. Katzensteiner, P. Reiter, C. Stummer, M. Denk, Multi-objective decision analysis for competence-oriented project portfolio selection, Eur. J. Oper. Res. 205 (3) (2010) 670-679.

[38] L. Herlocker, J.A. Konstan, L.G. Terveen, J.T. Riedl, Evaluating collaborative filtering recommender systems, ACM Trans. Inf. Syst. 22 (1) (2004) 5-53.

[39] F.G. Hilton-Price, Handbook of London Bankers, Chatto and Windus, London, 1876.

[40] G. Hu, L. Wang, S. Fetch, B. Bidanda, A multi-objective model for project portfolio selection to implement lean and Six Sigma concepts, Int. J. Prod. Res. 46 (23) (2008) 6611-6625.

[41] X. Huang, A new perspective for optimal portfolio selection with random fuzzy returns, Inf. Sci. 177 (23) (2008) 5404-5414.

[42] X. Huang, Mean-semivariance models for fuzzy portfolio selection, J. Comput. Appl. Math. 217 (1) (2008) 1-8.

[43] E.C.M. Hui, O.M.F. Lau, K.K. Lo, A fuzzy decision-making approach for portfolio management with direct real estate investment, Int. J. Strateg. Prop. Manage. 13 (2) (2009) 191-204.

[44] IBM, Wealth and Private Banking - Industry Survey 2005, IBM, London, 2005.

[45] IFIP, The Financial Exchange Framework Ontology, International Financial Information Publishing Ltd. (IFIP), 2003. <http://www.financial-format.com/ fef.htm> (accessed 11.03.10).

[46] T.Y. Kim, K.J. Oh, I. Sohn, C. Hwang, Usefulness of artificial neural networks for early warning system of economic crisis, Expert Syst. Appl. 26 (4) (2004) 583-590.

[47] P.C. Ko, P.C. Lin, Resource allocation neural network in portfolio selection, Expert Syst. Appl. 35 (1-2) (2008) 330-337.

[48] R. Kowalczky, On linguistic approximation with genetic programming, Methodol. Tools Knowl. Based Syst. (1998) $200-209$.

[49] G. Lakoff, Hedges: a study in meaning criteria and the logic of fuzzy concepts, J. Philos. Logic 2 (4) (1973) 458-508.

[50] W.M. Lassar, C. Manolis, R.D. Winsor, Service quality perspectives and satisfaction in private banking, J. Serv. Mark. 18 (3) (2000) $244-274$.

[51] J.T. Liang, X.Y. Jiang, A software component classification based on facet and neural network, in: International Symposium on Intelligent Information Technology Application Workshops, 2008, pp. 1121-1123.

[52] C.C. Lin, Y.T. Liu, Genetic algorithms for portfolio selection problems with minimum transaction lots, Eur. J. Oper. Res. 185 (1) (2008) $393-404$.

[53] C. Lin, P.J. Hsieh, A fuzzy decision support system for strategic portfolio management, Decis. Support Syst. 38 (2004) 383-398.

[54] C. Lin, B. Tan, P.J. Hsieh, Application of the fuzzy weighted average in strategic portfolio management, Decis. Sci. 36 (3) (2005) 489-511.

[55] J. Liu, W. Wang, F. Golnaraghi, E. Kubica, A neural fuzzy framework for system mapping applications, Knowl. Based Syst. 23 (6) (2010) 572-579.

[56] T. Magoc, X. Wang, F. Modave, Applications of fuzzy measures and interval computation to financial portfolio selection, Int. J. Intell. Sys. 25 (7) (2010) 621-635.

[57] J.H. Min, C.A. Jeong, A binary classification method for bankruptcy prediction, Expert Syst. Appl. 36 (3) (2009) 5256-5263. Part 1.

[58] N.M.N. Muhammad, Behavioural finance vs traditional finance, Adv. Manage. 2 (6) (2009) 1-10.

[59] E. Pap, Z. Bosnjak, S. Bosnjak, Application of fuzzy sets with different t-norms in the interpretation of portfolio matrices in strategic management, Fuzzy Sets Syst. 114 (1) (2000) 123-131.

[60] PricewaterhouseCoopers, A New Era: Redefining Ways to Deliver Trusted Advice Global Private Banking and Wealth Management Survey, PricewaterhouseCoopers, 2009. <http://www.pwc.com/gx/en/private-banking-wealth-mgmt-survey/pbwm09.html>.

[61] A. Rodríguez-González, A. García-Crespo, R. Colomo-Palacios, F. Guildrís-Iglesias, J.M. Gómez-Berbis, CAST: using neural networks to improve trading systems based on technical analysis by means of the RSI financial indicator, Expert Syst. Appl. 38 (9) (2011) 11489-11500. http://dx.doi.org/10.1016/ j.eswa.2011.03.023.

[62] T.J. Ross, Fuzzy Logic with Engineering Applications, Wiley Online Library, 1995.

[63] M.F. Shipley, Portfolio management: a fuzzy set based approach to monitoring size to maximize return and minimize risk, World Acad. Sci. Eng. Technol. 52 (2009) 506-513.

[64] J.Y. Shyng, H.M. Shieh, G.H. Tzeng, S.H. Tzeng, An integration method combining rough set theory with formal concept analysis for personal investment portfolios, Knowl. Based Syst. 23 (6) (2010) 586-597.

[65] C. Stummer, E. Riesling, W.J. Gutjahr, A multicriteria decision support system for competence-driven project portfolio selection, Int J. Inf. Technol. Decis. Making 8 (2) (2009) 379-401.

[66] Z. Sudebar, M. McCrae, D. Gerace, The validity of financial advisor's heuristic risk tolerance categorisation: evidence from a risk tolerance assessment tool, in: European Financial Management Association 2007 Annual Meetings, 2007.

[67] A.A. Thompson, A.J. Strickland, Strategic Management Concepts and Cases, IRWIN Homewood, Boston, 1992.

[68] M.N. Uddin, P. Janecek, Faceted classification in web information architecture: a framework for using semantic web tools, Electron. Lib. 25 (2) (2007) 219-233.

[69] J. Ulrich, Private real estate management in private banking, Uhlenbruch Verlag, Frankfurt, 2001.

[70] A. Usoro, I.U. Khan, Trust as an aspect of organisational culture: its effects on knowledge sharing in virtual communities, Int J. Hum. Cap. Inf. Technol. Prof. 2 (1) (2011) 1-17, http://dx.doi.org/10.4018/jhcitp.2011010101.

[71] H.F. Wang, W.U. Cheng-Ting, A strategy-oriented operation module for recommender systems in E-commerce, Comput. Oper. Res. 39 (8) (2012) 18371849.

[72] C. Whitrow, D.J. Hand, P. Juszczak, D. Weston, N.M. Adams, Transaction aggregation as a strategy for credit card fraud detection, Data Min. Knowl. Discov. 18 (1) (2009) 30-55.

[73] L. Yan, Risk curve and bifuzzy portfolio selection, J. Math. Res. 1 (2) (2009) 193-198.

[74] I.C. Yeh, C.H. Lien, The comparisons of data mining techniques for the predictive accuracy of probability of default of credit card clients, Expert Syst. Appl. 36 (2) (2009) 2473-2480. Part 1.

[75] L. Yu, S. Wang, K.K. Lai, An intelligent-agent-based fuzzy group decision making model for financial multicriteria decision support: the case of credit scoring, Eur. J. Oper. Res. 195 (3) (2009) 942-959.

[76] L. Yu, S. Wang, K.K. Lai, Neural network-based mean-variance-skewness model for portfolio selection, Comput. Oper. Res. 35 (1) (2008) 34-46.

[77] M. Yu, H. Inoue, S. Takahashi, J. Shi, Dynamic portfolio selection with uncertainty, Int. J. Uncertain. Fuzz. Knowl. Based Syst. 17 (2) (2009) 237-250.

[78] L. Zadeh, Fuzzy sets, Inf. Contr. 8 (3) (1965) 338-353.

[79] M. Zanker, M. Jessenitschnig, Case-studies on exploiting explicit customer requirements in recommender systems, User Model. User-adapt. Interact. 19 (2009) 133-166.

[80] M. Zanker, M. Jessenitschnig, W. Schmid, Preference reasoning with soft constraints in constraint-based recommender systems, Constraints 15 (2010) 574-595.

[81] L. Zhou, K.K. Lai, L. Yu, Credit scoring using support vector machines with direct search for parameters selection, Soft Comput. - A Fusion Found. Methodol. Appl. 13 (2) (2009) 149-155. 